\title{
miR-1273h-5p Suppresses the Penetration and Pervasion of Gastric Cancer Cells via Suppressing CXCL12 Expression
}

\section{Yi-Chen Wang}

Chinese PLA General Hospital

\section{Song Lu}

Xuanwu Hospital Capital Medical University

\section{Xiao-Jiang Zhou}

Chinese PLA General Hospital

Li Yang

Xuanwu Hospital Capital Medical University

ping liu

Chinese PLA General Hospital

\section{Lan Zhang}

Xuanwu Hospital Capital Medical University

\section{Yuan Hu}

Chinese PLA General Hospital

Xian-Zhe Dong ( $\sim$ dongxianzhe@163.com )

Capital Medical University

\section{Research}

Keywords: Gastric cancer, miR-1273h-5p, Proliferation, Apoptosis, Migration, Invasion

Posted Date: October 27th, 2021

DOI: https://doi.org/10.21203/rs.3.rs-986725/v1

License: (1) (1) This work is licensed under a Creative Commons Attribution 4.0 International License. Read Full License 


\section{Abstract}

Purpose: microRNAs (miRNAs), which may function as oncogenes or tumor suppressors, have been verified in the development of breast carcinoma, melanoma, and some other tumors. The dysregulated miR-1273h-5p in tissue samples of gastric cancer (GC) may be involved in the progression of GC. The aim of this study was to verify the biological function of miR-1273h-5p in GC progression.

Method: The differential expression of microRNAs between GC and tumor-adjacent normal tissues was detected by microarrays, and polymerase chain reaction (PCR) analysis was used for miR-1273h-5p and chemokine (C-X-C motif) ligand 12 (CXCL12) mRNA expressions. The effect of miR-1273h-5p on cell proliferation and apoptosis was evaluated by CCK-8 assay and flow cytometry; cell migration and invasion were observed by using the transwell method. In addition, protein levels were determined by Western blot. SGC-7901 cell transfected gene sequences were injected into BALB/c-nu mice to establish a xenograft model in order to validate the biological function of miR-1273h-5p in vivo.

Results: Compared to tumor-adjacent normal tissue and GES-1 cells, miR-1273h-5p was significantly down-regulated in tissues and cells of GC. The overexpression of miR-1273h-5p could inhibit cell proliferation, migration, invasion, and promote cell apoptosis; in contrast, inhibition of miR-1273h-5p expression could reverse this process. Moreover, a significant up-regulation of CXCL12 was observed when the miR-1273h-5p was down-regulated in GC cells. Additionally, tumor tissues were collected from mice after 21 days of feeding, revealing that miR-1273h-5p significantly reduces tumor volume and tumor weight.

Conclusions: miR-1273h-5p regulates cell proliferation, migration, invasion, and apoptosis during GC progression by directly binding to CXCL12 mRNA 3'-UTR, thus can be used as a potential diagnostic and a novel therapeutic target for $\mathrm{GC}$ in clinical practice.

\section{Introduction}

The global incidence and mortality rate of gastric cancer (GC) are relatively high (1-3). Over 70\% of cases occur in developing countries (4), especially China (5). In addition, most GC patients are diagnosed at the advanced stage with extensive involvement of regional lymph nodes or the metastasis to distant organs $(6,7)$ due to non-specific symptoms during the early stage (8). Moreover, the invasion and metastasis of tumors are the most common reasons for the death from GC (9), and more than $90 \%$ of mortality in GC patients is caused by distal metastasis (10). Although a series of diagnostic technologies and novel treatment strategies have been developed and available for GC patients, surgery and chemotherapy remain the predominant treatment options, and the high rate of lymph node metastasis and poor survival still remains the major obstacles to successful treatment in the clinical practice (11-14). Nowadays, many investigations have been carried out to assess the etiology of GC (15-17). Nevertheless, the molecular mechanisms underlying the pathogenesis and development of GC remain largely 
unexplored. Therefore, it is urgently necessary to elucidate molecular mechanisms and identify novel biomarkers for the diagnosis, treatment and prognosis of GC patients.

microRNAs (miRNAs), which are endogenous non-coding RNAs with a length of about 19-24 nucleotides, can modulate the translation and stability of their target messenger RNAs (mRNAs) by binding to complementary sequences of 3 '-untranslational regions (3'-UTR) of the transcripts (18). Numerous studies have confirmed the correlation between the altered expressions of miRNAs and cancer since the dysregulation of miRNAs participates in several important processes during carcinogeneses (5), such as cell growth, differentiation, and apoptosis (19). For example, reduced expression of miR-215 has been observed in breast cancer, and the over-expression of miR-215 leads to the suppressed growth and penetration of breast cancer cells by targeting AKT1 (20). The up-regulated miR-223-3p enhances the cell proliferation, migration, and invasion in ovarian cancer by targeting SOX11 (21). Similarly, the upregulated miR-106b in cancer-associated fibroblasts of GC patients can accelerate the invasion by regulating PTEN (22). Therefore, miRNAs can be used as novel therapeutic targets for cancers.

Recently, the critical role of miRNAs in the development of GC has been explored, and miR-106a (23), miR181b (24), and miR-21 (25)have been identified to modulate the growth, migration, and penetration in GC cells. In our current work, we showed that the expression of miR-1273h-5p was dramatically decreased in GC tissues and GC cells; nonetheless, it remained unclear whether miR-1273h-5p can also regulate the cell pervasion, apoptosis, migration, and penetration during the progression of GC. To solve this issue, we evaluated the underlying mechanisms of miR-1273h-5p in the development of GC. Collectively, our findings provide valuable insights into the diagnosis, prognosis and therapeutic regime of GC patients.

\section{Materials And Methods \\ 2.1 Microarray analysis}

A total of 53 pairs of GC and tumor-adjacent normal tissue samples were collected from patients admitted to our hospital between July 2015 and December 2016, and three pairs of these samples were used for microarray analysis. The tumor-adjacent normal tissues were dissected at $3 \mathrm{~cm}$ from the edge of tumors. Microarray assay and bioinformatics analysis (Gen ontology (GO) and Kyoto Encyclopedia of Genes and Genomes (KEGG) pathway) were performed as described in our previous study (26). Briefly, approximately $1 \mu \mathrm{g}$ of total RNA was conjugated with polyA tail using FlashTag ${ }^{\text {TM }}$ Biotin HSR Labeling Kit (Affymetrix, Santa Clara, CA, USA). Hybridization was carried out with the labeled RNA at $48^{\circ} \mathrm{C}$ for $16 \mathrm{~h}$ with shaking at $60 \mathrm{rpm}$ for Affymetrix miRNA 4.0 Array. A robust Multichip Analysis (RMA) algorithm was used to analyze the data. The mRNA-miRNA interaction was predicted using the micode database (http://www.mircode.org/). According to the measured values of mRNA and TarBase database (http://www.microrna.gr/tarbase) forecasts, the miRNA target genes mRNA were determined. Combined with the actual differential mRNAs detected by microarray, the negative correlation between miRNAmRNA was obtained. After predicting the target genes, GO and KEGG pathway analyses were performed. The purpose of these analyses was to identify differentially expressed genes (DEGs) between groups. 
The data were analyzed by Fisher's exact test. The $P$-value was calculated using the Benjamini-Hochberg step-up procedure, followed by rectification using the false discovery rate (FDR) method. $\mathrm{P} \leq 0.05$ was regarded as statistically significant. Meanwhile, enrichment scores were adopted to determine the enrichment level for the GO pathway.

\subsection{Cell culture conditions}

Human GC cell lines that were used in this study (MGC-803, BGC-823, and SGC-7901, MKN-45) and normal gastric epithelial mucosa cell line (GES-1) were provided by Cancer Hospital Chinese Academy of Medical Sciences (Beijing, China). GC cells were maintained in RPMI-1640 medium (BioTeke Corporation, Beijing, China), and GES- 1 cells were maintained in DMEM medium in a condition of $37^{\circ} \mathrm{C}$ containing $5 \%$ $\mathrm{CO}_{2}$. Each medium used for cell culture contained $10 \%$ fetal bovine serum (FBS, Thermo Fisher Scientific, Inc., Waltham, MA, USA).

\subsection{RT-qPCR}

Gastric cancer cells and GES- 1 cells were seeded into 6 -well plates at a density of $2 \times 10^{5}$ cells/well, maintained at $37^{\circ} \mathrm{C}$ with $5 \% \mathrm{CO}_{2}$ until the confluence of the cells reached $80-90 \%$. miRNAs were extracted by using miRcute miRNA isolation kit (TIANGEN, Beijing, China). The concentration and purity of miRNA were determined by NanoDrop-2000. The miRNAs were reversely transcribed into complementary DNAs (cDNAs) by miRcute Plus miRNA First-Strand cDNA Synthesis Kit (TIANGEN, Beijing, China), and RT-qPCR was conducted by using miRcute Plus miRNA qPCR Detection Kit (SYBR Green) (TIANGEN, Beijing, China) according to the manufacturer's instructions. Briefly, initial denaturation step: $94^{\circ} \mathrm{C}$ for 2 min, melting: $94^{\circ} \mathrm{C}$ for $20 \mathrm{~s}$, annealing: $60^{\circ} \mathrm{C}$ for $34 \mathrm{~s}$. U6 and GAPDH were selected as the housekeeping genes. The primers were synthesized by AuGCT (AuGCT, Beijing, China) as follows: miR-1273h-5p-F: 5'-

CTGGGAGGTCAAGGCTGCAGT-3', miR-1273h-5p-R: 5'-ACTGCAGCCTTGACCTCCCAG-3'; U6-F: 5'-

AATCTAGCTGCTGCGGTTCC-3', U6-R: 5'-GGAACCGCAGCAGCTAGATT-3'; CXCL12-F:5'-

CAGATGCCCATGCCGATT-3', CXCL12-R: 5'TCTGAAGGGCACAGTTTGGA-3'; GAPDH-F: 5'-

GTGGAGTCCACTGGCGTCTT-3', GAPDH-R: 5'-GTGCAGGAGGCATTGCTGAT-3'. The relative expressions of target genes were calculated by the $2^{-\triangle \triangle C T}$ method.

\subsection{Western blot}

Western blotting analysis was used to analyze the expression of proteins. Briefly, cell lysis was performed using RIPA buffer containing protease and phosphatase inhibitor cocktails, and the protein concentrations were determined by BCA assay. Subsequently, proteins $(50 \mu \mathrm{g})$ mixed with the right concentration were subjected to sodium dodecyl sulfate-polyacrylamide gel electrophoresis (SDS-PAGE) for separation, after which they were electro-transferred onto a PVDF membrane. After blocking with $5 \%$ BSA for $3 \mathrm{~h}$ at room temperature, the membranes were incubated with primary antibodies (CXCL12, Proteintech, 17402-1-AP; $\beta$-tubulin, Immunoway, YM3030; GAPDH, Immunoway, YM3029) at $4^{\circ} \mathrm{C}$ overnight followed by incubation with corresponding secondary antibodies (HRP-conjugated Affinipure Goat Anti-Rat IgG (H+L), proteintech, SA00001-15) for $2 \mathrm{~h}$. Immunoreactive bands were visualized by a 
chemiluminescence kit, and the density of the bands was determined by scanning densitometry (Bio-Rad, Hercules, CA).

\subsection{Cell transfection and Luciferase reporter assay}

As described in our previous studies (27), miR-1273h-5p expression plasmid including mimics, inhibitors, and empty plasmid (GV268) were provided by GeneChem Co., Ltd. (Shanghai, China). In this study, "normal con" cells were not transfected, and "negative con" cells were transfected with empty vector. The wild-type and mutant CXCL12 plasmids were also prepared by GeneChem Co., Ltd. and cloned into firefly luciferase plasmid GV272 (GeneChem). miRNA mimic is a plasmid that can increase the level of miR1273h-5p, and miRNA inhibitor can inhibit the endogenous level of miR-1273h-5p. MGC-803, BGC-823, and SGC-7901 cells were cultivated in 96-well plates $\left(5 \times 10^{3}\right.$ cells/well) and then transfected with miR$1273 \mathrm{~h}-5 \mathrm{p}$ mimics, inhibitors, or corresponding negative plasmids with the concentration of $0.3 \mu \mathrm{g} / \mu \mathrm{L}$. Transfection reagent Lipofectamine 2000 (Thermo Fisher Scientific, Inc.) was used with a concentration of $0.2 \mu \mathrm{L}$ (96-well plates).

In Luciferase Reporter Assay, plasmids containing target gene (CXCL12) and miR-1273h-5p mimics were co-transfected into HEK-293 cells, which were purchased from FuHeng Bio Co., Ltd.( Shanghai, China). HEK-293 cells were suspended at $1.0 \times 10^{5}$ cells $/ \mathrm{mL}$ in DMEM containing $10.0 \% \mathrm{FBS}$, then seeded into a 96-well plate $\left(1 \times 10^{4}\right.$ cells/well). The CXCL12 firefly luciferase plasmids (GeneChem Co., Ltd. Shanghai, China) were pre-transfected, after which miR-1273h-5p plasmids were transfected (Figure S1a). Then, pRL-TK Renilla luciferase vectors (Promega, Madison, WI, USA) were transfected. Finally, the luciferase activity was determined using Dual-Glo Luciferase Assay System (Promega). All experiments were repeated three times.

During the construction of the target gene, 3 sequences capable of constructing CXCL12 distributing in the two transcripts were found, so two plasmids were constructed, which were labeled 1,2 (Figure S1b-d).

\subsection{Cell proliferation assay}

MGC-803, BGC-823, and SGC-7901 cells were seeded into 96 -well plates $\left(5 \times 10^{3}\right.$ cells/well) with $200 \mu \mathrm{L}$ of RPMI-1640 medium. After $24 \mathrm{~h}$ of culture, cells were transfected with $1 \mu \mathrm{L}(0.3 \mu \mathrm{g} / \mu \mathrm{L})$ of miR-1273h-5p mimics or inhibitors. Cells in the negative control group were transfected $1 \mu \mathrm{L}(0.3 \mu \mathrm{g} / \mu \mathrm{L})$ empty plasmid, and blank control cells were without transfection. After $24 \mathrm{~h}$ incubation, $20 \mu \mathrm{L}$ CCK-8 reagent was added to each well according to the manufacturer's protocols. The 96 -well plates were kept incubated for $4 \mathrm{~h}$. Then cell viability was evaluated by using 1420 Multilabel Counter (PerkinElmer, USA) according to the absorbance at $450 \mathrm{~nm}$. Each experiment containing five replicated samples was conducted in triplicate.

\subsection{Cell apoptosis analysis}

GC cells were seeded into 6 -well plates $\left(1 \times 10^{6} \mathrm{cells} /\right.$ well), followed by $24 \mathrm{~h}$ incubation. Subsequently, the cells of "negative con" and "mimics" group cells were transfected with $2 \mu \mathrm{g}$ of empty plasmid or miR1273h-5p mimic plasmid, respectively. After $24 \mathrm{~h}$, the cells were collected. After washing with PBS, cells 
were resuspended with $1 \mathrm{X}$ Binding Buffer to achieve a concentration of $5 \times 10^{6} \mathrm{cell} / \mathrm{mL}$. Then, cells were stained with Annexin-V FITC and propidium lodide Apoptosis Detection Kit (Invitrogen) according to the manufacturer's protocols. Apoptosis data were analyzed using flow cytometry (FCM, BD Biosciences, Calibur, USA) and Cellquest software. The number of apoptotic cells was equal to the sum of early apoptotic cells and late apoptotic cells. All experiments were conducted in triplicate.

\subsection{Transwell assays of tumor cell migration and invasion}

The transwell assay (Corning, USA) was performed to evaluate cell migratory and invasive capacities of GC cells. For cell invasion assay, Matrigel matrix (CORNING, 354234, $10.7 \mathrm{mg} / \mathrm{ml}$ ) required prior preparation. The Matrigel matrix $(3.35 \mathrm{mg} / \mathrm{ml})$ was pre-coated on the top of the upper chamber. The miR$1273 \mathrm{~h}-5 \mathrm{p}$-transfected or control vector-transfected cells were suspended at $5.0 \times 10^{5} \mathrm{cells} / \mathrm{mL}$ in serumfree DMEM, reserving for the next step. Briefly, the upper and bottom transwell chambers (24-well plates) were coated with $100 \mu \mathrm{L}$ serum-free medium and $600 \mu \mathrm{L}$ containing $20 \% \mathrm{FBS}$, respectively. The cells were incubated for $24 \mathrm{~h}$. The cells that did not migrate to the lower surface of the membranes were removed from the upper surface of the transwell chamber by a cotton swab. Those migrated cells were stained with $0.1 \%$ crystal violet solution. Cell Migration Assay was the same as invasion assay, except the upper chambers did not need to be coated with Matrigel matrix. Images were then captured under a digital microscope (Olympus IX81, Japan), the number of cells was counted by the experimenter in five randomly selected fields for each group; all results were presented as Mean \pm SD.

\subsection{Xenograft tumor model}

Male BALB/c-nu mice ( $n=30)$ weighing 14.0 to $17.0 \mathrm{~g}$, aged 4 weeks, were housed in an environment with a temperature of $22 \pm 1^{\circ} \mathrm{C}$, relative humidity of $50 \pm 1 \%$, and a light/dark cycle of $12 / 12 \mathrm{hr}$. All animal studies (including the mice euthanasia procedure) were done in compliance with the regulations and guidelines of PLA medical school institutional animal care and conducted according to the AAALAC and the IACUC guidelines.

The mice were randomly divided into three groups after being given adaptive feeding under specificpathogen-free for 5 days. GC cells SGC-7901 and the cells transfected with miR-1273h-5p mimics or corresponding negative plasmid were suspended at $2 \times 10^{6}$ cells $/ \mathrm{ml}$ in RPMI -1640 containing $10.0 \%$ FBS. Then, mice in each group were subcutaneously injected $0.2 \mathrm{ml}$ above-mentioned cells suspension into the right forearm close to the axilla. Tumor volume and weight were carefully measured until mice were sacrificed after three weeks of feeding. Volume $(V)$ was monitored by measuring the tumor length $(L)$ and width $(W)$ with standard calipers and calculated with the formula of $V=\left(L \times W^{2}\right) \times 0.5$. Next, the obtained tumor tissues were used for Polymerase Chain Reaction (PCR) and Western blot respectively.

\subsection{Statistical analysis}

SPSS22.0 and GraphPad prism 5.0 (GraphPad Software Inc., San Diego, CA) were adopted for all statistical analyses. Each experiment was repeated three times. Data were verified using t-test and expressed as mean \pm standard deviation. Microarray analysis and KEGG pathways of DEGs were analyzed 
using the standard statistical function of hypergeometric distribution, $t$-test, and FDR. $P \leq 0.05$ was regarded as statistically significant.

\section{Results}

\subsection{Clinicopathological features of the GC patients}

In the present study, we collected 53 GC samples from clinical data. The clinicopathological features, such as gender, age, tumor size, differentiation, lymph node metastasis, HP infection, and serum CA125 level, were synthesized in statistics. There were $60.38 \%$ males and $39.62 \%$ females in this cohort, and the age of all collected GC patients ranged from 28 to 72 years, with an average age of 53 years (Table 1 ).

\subsection{Differentially expressed miRNAs in GC tissues and cells}

The miRNA microarray assay was conducted to identify the differentially expressed miRNAs between gastric tissues and tumor-adjacent normal tissues. In these GC tissue samples, 19 miRNAs were overexpressed compared with the tumor-adjacent normal tissues (ratio > 1.5), and 17 miRNAs were downregulated with a reduction by 1.5 -fold or more (ratio $<0.667$ ), including hsa-miR-1273h-5p (Figure 1a)

Next, the expression of miR-1273h-5p in GC tissues (from 53 GC patients with gastrectomy) was downregulated by 0.31 -fold compared with the tumor-adjacent normal tissues (NC)(Figure 1b). The expression of miR-1273h-5p in human GC cell lines, such as MGC-803, BGC-823, SGC-7901 and MKN-45 cells, and GES-1 cells was validated by RT-PCR. As shown in Figure 1c, the expression of miR-1273h-5p was decreased in four GC cell lines compared with the normal GES-1 cell line. miR-1273h-5p expression was not detected in MKN-45 cells. Therefore, MGC-803, BGC-823, and SGC-7901 cells were chosen for the further biological function analysis of miR-1273h-5p.

\subsection{Impact of miR-1273h-5p on the growth and apoptosis of GC cells}

Because the miR-1273h-5p expression was significantly low in GC, we speculated that it might inhibit the growth of GC cells and enhance cell apoptosis. To validate our hypotheses, we up-regulated the miR1273h-5p expression by transfecting BGC-823, MGC-803, and SGC-7901 cells with miR-1273h-5p mimics, and down-regulated the miR-1273h-5p expression by transfecting miR-1273h-5p inhibitors into the abovementioned cells. Subsequently, a CCK-8 assay was conducted after $48 \mathrm{~h}$ of transfection to explore the impact of miR-1273h-5p on the viability of BGC-823, MGC-803, and SGC-7901 cells. When transfected with mimics, the viability of BGC-823, MGC-803, and SGC-7901 cells significantly decreased compared with negative and normal control groups (Figure $2 \mathbf{a}, \mathbf{c}, \mathbf{e}$ ). In contrast, the viability of the above-mentioned cells transfected with inhibitors was increased, especially MGC-803 and SGC-7901 that were significantly increased compared to negative control groups (Figure $\mathbf{2 b}, \mathbf{d}, \mathbf{f}$ ). To sum up, the over-expression of miR1273h-5p suppressed the growth of BGC-823, MGC-803, and SGC-7901 cells while miR-1273h-5p inhibitor promoted the growth of MGC-803 and SGC-7901 cells. 
PI and Annexin V-FITC staining were adopted to assess the apoptotic ability of cells after the transfection of miR-1273h-5p mimics. The proportion of apoptotic cells was determined using flow cytometry (FCM) (Figure 3a). After the cells were transfected with miR-1273h-5p mimics, the apoptotic rates of BGC-823, MGC-803, and SGC-7901 cells were dramatically enhanced (Figure 3b) compared with corresponding negative control groups. These findings revealed the effect of miR-1273h-5p and indicated that it had a fundamental role in regulating the apoptosis of GC cells. Three samples from each group were selected for the experiment.

\subsection{Effect of miR-1273h-5p on the migration and invasion of GC cells}

Cell migration and invasion were explored using the transwell assay, and the number of migratory and invasive cells was counted using a microscope (100x, 200x). Finally, three random visual fields from each kind of GC cell group were confirmed for counting statistics. Results indicated that the overexpression of miR-1273h-5p inhibited the migration of BGC-823 and SGC-7901 cells (Figure 4). In addition, the invasion of BGC-823, MGC-803 and SGC-7901 cells were also inhibited by over-expression of miR-1273h-5p compared to normal and negative control groups (Figure 5).

\subsection{High expression of miR-1273h-5p down-regulates CXCL12}

In order to explore the target genes of miR-1273h-5p, bioinformatics analysis was conducted using TargetScan and miRanda software, and CXCL12 was identified as a target gene (Figure 6a). Numerous investigations have shown that extracellular CXCL12 is over-expressed in different types of tumors. To verify the relationship between miRNA and target gene, prepared plasmids including miRNA, target gene, and reference genes were all transfected into HEK293 cells. According to target gene plasmids, different groups were set for comparative analysis, such as CXCL12-normal control, CXCL12-wild type1, CXCL12mutation1, CXCL12-wild type2, CXCL12-mutation2. Since CXCL12 has two transcripts, we set up two more groups when we customized its plasmids. Then, miRNA plasmid miR-1273h-5p mimics and their corresponding negative control plasmids were transfected into the above groups, respectively. Renilla's internal reference was finally transfected into all groups. There was no effect of miR-1273h-5p negative control plasmids on the CXCL12 level (Figure 6b,d). However, Figure 6c,e show significant discrepancies that occurred on CXCL12-wild type 1,2, which received miR-1273h-5p mimics. In summary, high expression of miR-1273h-5p could down-regulate CXCL12. These results indicated that miR-1273h-5p could bind to the wild type rather than the mutant type.

\subsection{Binding to the target gene CXCL12 in GC cells}

A negative regulatory relationship was found between miR-1273h-5p and CXCL12. Therefore, we aimed to assess the expression of CXCL12 in terms of mRNA and protein by RT-qPCR and Western blotting, respectively. The CXCL12 expression at the mRNA level was dramatically down-regulated in GC cells transfected with miR-1273h-5p mimics (Figure 7a). Similarly, the protein expression of CXCL12 was also obviously reduced (Figure 7b,f). These results suggested that miR-1273h-5p could inhibit the viability, migration, and penetration of GC cells by down-regulating the expression of CXCL12. 


\subsection{In vivo validation}

The xenograft tumor model in nude mice was established to verify these conclusions further. The volume and weight of tumor tissue were measured after 21 days of feeding. The tumor volume of the miR-1273h$5 p$ mimic group $(n=10)$ was significantly lower than that of the normal control group $(n=10)$ and negative control group $(n=10)$. Similarly, the statistical discrepancies of tumor weight were found in the miR1273h-5p mimic group as well (Figure 8a,b).

Next, we obtained the levels of miRNAs by RT-PCR detection and ensured that plasmids were successfully transfected as the trial group had a significant over-expressed level (Figure 8c). CXCL12 mRNA was also detected and the expression of the miR-1273h-5p group was significantly lower compared to both normal and negative control groups (Figure 8d). Subsequently, the protein detection by Western blot yielded consistent results with previous CXCL12 mRNA consequences (Figure $8 \mathbf{e}, \mathbf{f}$ ). The protein expression remarkably decreased in miR-1273h-5p group. These results supported a close correlation between miR1273h-5p and CXCL12, which also verified the function of miR-1273h-5p in gastric cancer.

\section{Discussion}

It is well known that the dysfunction of miRNAs is tightly correlated with the pathogenesis of different human tumors, thus indicating that miRNAs may function as oncogenes or tumor suppressors (28). Many dysregulated miRNAs, such as miR-30b, miR-372, and miR-21, have been shown to be involved in the growth, apoptosis, migration, and penetration of GC cells (29-31). In our current work, miR-1273h-5p was lowly expressed in GC tissues and cell lines, while the over-expression of miR-1273h-5p could suppress the growth and penetration of GC cells and enhance their programmed death.

The expression of miR-1273 is frequently found to be dysregulated in various kinds of diseases. For example, miR-1273d and miR-1273g-3p have been associated with different types of cancers, such as progressive lymphoma, diffused melanoma neoplasm metastasis, neoplasm skin neoplasms, uterine and cervical neoplasms (32). Moreover, miR-1273g-3p is also significantly dysregulated in patients with chronic obstructive pulmonary disease (COPD)(33). The up-regulation of miR-1273 was detected in the KrasG12D Pdx1-Cre pancreatic cancer mouse model compared with the control mice (34). The downregulation of miR-1273 in early atherosclerotic plaque tissues has been confirmed, and the specific regulatory pattern of miRNAs in early atherosclerotic plaques may be useful in determining the formation and stability of plaques (35). In our current work, the expression of miR-1273h-5p was reduced in GC tissues and cell lines, thus indicating its function as a tumor suppressor gene in human GC.

Apoptosis is a form of programmed cell death that occurs in multicellular organisms under physiological and pathological conditions (36). Cancer cells often over-express many of the proteins that have important roles in resisting the activation of apoptotic cascade (37). The patients may experience tumor progression when the normal apoptosis process is disrupted (38). We found that the abnormal expression of miR-1273h-5p triggered a greater apoptotic rate of GC cells than the control cells in vitro. 
These findings indicated that miR-1273h-5p participated in the pathogenesis of GC by enhancing the apoptosis of tumor cells.

Metastasis greatly contributes to mortality in GC patients (39). Most malignant cells from the primary tumor infiltrate into the surrounding parenchyma and enter into the circulation by blood vessel intravasation (40). Since we found that the expression of miR-1273h-5p was down-regulated in GC tissues and cell lines, we presumed that the over-expression of miR-1273h-5p could suppress the metastasis of GC cells. In an animal model, over-expressed miR-1273h-5p group exhibited significant differences in terms of tumors size and weight compared to other groups. In fact, the over-expression of miR-1273h-5p significantly inhibited the metastasis in BGC-823, SGC-7901, and MGC-803 cells, thus strongly suggesting the suppressive effect of miR-1273h-5p on gastric carcinoma. In addition, the downregulation of miR-1273h-5p in GC cells might promote the progression of GC.

As an important a-chemokine, CXCL12 is ubiquitously expressed in many types of tissues and cells. Previous studies have reported that CXCL12 can be a major factor in the recruitment of hematopoietic stem and progenitor cells (HSPCs)(41). It can also regulate the functional properties of the hematopoietic niche (42). When chemoattractant cytokines, such as CXCL12, are shedding and released by AMD3100, hematopoietic stem and progenitor cell (HSPC) mobilization is rapidly induced, which laterally reflects the role of CXCL12 in hematopoietic function (43). Moreover, human first-trimester trophoblast cells (TCs)derived CXCL12 can promote the migration and invasion of human first-trimester decidual epithelial cells (DECs) (44). Also, CXCL12 causes neural stem cells (NSCs) death during brain injury and diseases by inducing apoptosis (45). Another research validated that CXCL12 significantly increases endothelial progenitor cell (EPC) viability by MTS viability assay (46). Besides, overexpression of CXCL12 can promote the growth of human breast cancer cells, which has been documented (47), exacerbating nasopharyngeal carcinoma (NPC) cell migration and invasion (48) and primarily functioning by binding to its receptor CXCR4. The activation of various signaling pathways that are correlated with chemotaxis, cell survival, and proliferation may trigger the intracellular binding signaling of CXCL12 to CXCR4 (49). Recently, it has been shown that CXCL12 binds to CXCR7 to mediate the trafficking of normal and tumor cells (50). Both receptors have critical roles in the metastasis of different tumors, and they can function as tumor biomarkers and potential therapeutic targets $(51,52)$. The relative ratio of CXCL12 to its receptors CXCR4 or CXCR7 may be a better indicator of CXCL12 activity (53), and differences may exist in these ratios representing diverse cancer types $(54,55)$. The activation of the CXCL12/CXCR4/CXCR7 axis participates in the growth and metastasis of tumors, promoting tumors spreading to distant organs and the formation of secondary tumors (56).

Several studies have demonstrated that the expression of some chemokines and their corresponding receptors are increased in GC tissues compared with normal gastric tissues (57). Moreover, primary GC tissues are CXCR4/CXCL12 positive, and such positive CXCR4 staining is tightly correlated with the metastasis of lymph nodes, higher TNM staging, and poor prognosis $(54,58)$. CXCL12 can also promote the expressions of epidermal growth factor receptor (EGFR) ligands, such as amphiregulin and heparin- 
binding EGF-like growth factor, in GC cells, leading to increased migration (59). The CXCR7/CXCL12 axis is involved in lymph node and liver metastasis of GC (60).

We found that the expressions of CXCL12 mRNA were down-regulated when miR-1273h-5p mimic transfected into BGC-823, MGC-803, and SGC-7901 cells in vitro. The expressions of CXCL12 protein also showed the same trends as mRNA. The results of luciferase reporter assay validated the correlation of miR-1273h-5p and CXCL12. Equally, the mRNA levels of CXCL12 were significantly decreased in the mice group with miR-1273h-5p over-expression compared with the negative group and normal group. The observed results of protein expressions were consistent with the former mRNAs' in a xenograft model.

Collectively, miR-1273h-5p functions as a tumor suppressor gene and participates in the pathogenesis of GC. The over-expression of miR-1273h-5p could suppress the cell growth and invasion and enhance the apoptosis of GC cells by directly binding to 3'-UTR of CXCL12 mRNA and regulating the CXCL12 expression. Therefore, miR-1273h-5p could be used as a new therapeutic regimen for gastric cancer patients.

\section{Declarations}

\section{Ethics approval and consent to participate}

The animal experiment was approved by the Ethics Committee of the Chinese PLA Hospital Medical Laboratory animal Center (China; Approval No. 2019-X15-85).

\section{Consent for publication}

Written informed consent for publication was obtained from all participants.

\section{Availability of data and material}

The data that support the findings of this study are available on request from the corresponding author. The data are not publicly available due to privacy or ethical restrictions.

\section{Competing interests}

The authors of this manuscript have no conflicts of interest to disclose.

\section{Funding}

National Natural Science Foundation of China (No. 81773778) and China Postdoctoral Science Foundation (2019M650775, 2020T130438)

\section{Authors' contributions}

Xian-Zhe Dong designed the experiment and wrote the manuscript; Ping Liu and Yuan Hu reviewed the manuscript for its intellectual content and revised the entire work; Xian-Zhe Dong, Yi-Chen Wang, Song 
Lu, Xiao-jiang Zhou and Li Yang performed the histological assessments and evaluations; Lan Zhang reviewed the manuscript for its intellectual content. All authors have read and approved the final manuscript.

\section{Acknowledgements}

Not applicable.

\section{References}

1. Ferro A, Peleteiro B, Malvezzi M, Bosetti C, Bertuccio P, Levi F, Negri E, Vecchia CL, Lunet N. Worldwide trends in gastric cancer mortality (1980-2011), with predictions to 2015, and incidence by subtype. Eur J Cancer. 2014;50(7):1330-44. doi:10.1016/j.ejca.2014.01.029.

2. Torre LA, Bray F, Siegel RL, Ferlay J, Lortet-Tieulent J, Jemal A. Global cancer statistics, 2012. CA Cancer J Clin. 2015;65(2):87-108. doi:10.3322/caac.21262.

3. Jemal A, Bray F, Center MM, Ferlay J, Ward E, Forman D. Global cancer statistics. CA Cancer J Clin. 2011;61(2):69-90. doi:10.3322/caac.20107.

4. Sasako M, Inoue M, Lin JT, Khor C, Yang HK, Ohtsu A. Gastric Cancer Working Group report. Jpn J Clin Oncol. 2010;40(Suppl 1):i28-37. doi:10.1093/jjco/hyq124.

5. Liu GH, Liu YH, Yang Z, Zhu AL, Zhao CL. MicroRNA-524-5p suppresses the growth and invasive abilities of gastric cancer cells. Oncol Lett. 2016;11(3):1926-32. doi:10.3892/ol.2016.4143.

6. Yang Q, Wang B, Gao W, Huang S, Liu Z, Li W, Jia J. SIRT1 is downregulated in gastric cancer and leads to G1-phase arrest via NF-KB/Cyclin D1 signaling. Mol Cancer Res. 2013;11(12):1497-507. doi:10.1158/1541-7786.Mcr-13-0214.

7. Maehara Y, Moriguchi S, Kakeji Y, Kohnoe S, Korenaga D, Haraguchi M, Sugimachi K. Pertinent risk factors and gastric carcinoma with synchronous peritoneal dissemination or liver metastasis.

Surgery. 1991;110(5):820-3.

8. Ferlay J, Shin HR, Bray F, Forman D, Mathers C, Parkin DM. Estimates of worldwide burden of cancer in 2008: GLOBOCAN 2008. Int J Cancer. 2010;127(12):2893-917. doi:10.1002/ijc.25516.

9. Nguyen DX, Bos PD, Massagué J. Metastasis: from dissemination to organ-specific colonization. Nat Rev Cancer. 2009;9(4):274-84. doi:10.1038/nrc2622.

10. Chaffer CL, Weinberg RA. A perspective on cancer cell metastasis. Science. 2011;331(6024):155964. doi:10.1126/science.1203543.

11. Sugano K. Screening of gastric cancer in Asia. Best Pract Res Clin Gastroenterol. 2015;29(6):895905. doi:10.1016/j.bpg.2015.09.013.

12. Zhang H, Sun LL, Meng YL, Song GY, Hu JJ, Lu P, Ji B. Survival trends in gastric cancer patients of Northeast China. World J Gastroenterol. 2011;17(27):3257-62. doi:10.3748/wjg.v17.i27.3257.

13. Maconi G, Manes G, Porro GB. Role of symptoms in diagnosis and outcome of gastric cancer. World J Gastroenterol. 2008;14(8):1149-55. doi:10.3748/wjg.14.1149. 
14. Sun F, Lu X, Li H, Peng Z, Wu K, Wang G, Tong Q. Special AT-rich sequence binding protein 1 regulates the multidrug resistance and invasion of human gastric cancer cells. Oncol Lett. 2012;4(1):156-62. doi:10.3892/ol.2012.681.

15. Zhang XT, Zhang Z, Xin YN, Ma XZ, Xuan SY. Impairment of growth of gastric carcinoma by miR-133mediated Her-2 inhibition. Tumour Biol. 2015;36(11):8925-30. doi:10.1007/s13277-015-3637-2.

16. Liu XH, Sun M, Nie FQ, Ge YB, Zhang EB, Yin DD, Kong R, Xia R, Lu KH, Li JH, De W, Wang KM, Wang ZX. Lnc RNA HOTAIR functions as a competing endogenous RNA to regulate HER2 expression by sponging miR-331-3p in gastric cancer. Mol Cancer. 2014;13:92. doi:10.1186/1476-4598-13-92.

17. Fassan M, Pizzi M, Realdon S, Balistreri M, Guzzardo V, Zagonel V, Castoro C, Mastracci L, Farinati F, Nitti D, Zaninotto G, Rugge M. The HER2-miR125a5p/miR125b loop in gastric and esophageal carcinogenesis. Hum Pathol. 2013;44(9):1804-10. doi:10.1016/j.humpath.2013.01.023.

18. Baek D, Villén J, Shin C, Camargo FD, Gygi SP, Bartel DP. The impact of microRNAs on protein output. Nature. 2008;455(7209):64-71. doi:10.1038/nature07242.

19. Bartel DP. MicroRNAs: genomics, biogenesis, mechanism, and function. Cell. 2004;116(2):281-97. doi:10.1016/s0092-8674(04)00045-5.

20. Yao J, Zhang P, Li J, Xu W. MicroRNA-215 acts as a tumor suppressor in breast cancer by targeting AKT serine/threonine kinase 1. Oncol Lett. 2017;14(1):1097-104. doi:10.3892/ol.2017.6200.

21. Fang G, Liu J, Wang Q, Huang X, Yang R, Pang Y, Yang M. MicroRNA-223-3p Regulates Ovarian Cancer Cell Proliferation and Invasion by Targeting SOX11 Expression. Int J Mol Sci, 18(6) (2017) doi:10.3390/ijms18061208.

22. Yang TS, Yang XH, Chen X, Wang XD, Hua J, Zhou DL, Zhou B, Song ZS. MicroRNA-106b in cancerassociated fibroblasts from gastric cancer promotes cell migration and invasion by targeting PTEN. FEBS Lett. 2014;588(13):2162-9. doi:10.1016/j.febslet.2014.04.050.

23. Zhu M, Zhang N, He S, Lui Y, Lu G, Zhao L. MicroRNA-106a targets TIMP2 to regulate invasion and metastasis of gastric cancer. FEBS Lett. 2014;588(4):600-7. doi:10.1016/j.febslet.2013.12.028.

24. Guo JX, Tao QS, Lou PR, Chen XC, Chen J, Yuan GB. miR-181b as a potential molecular target for anticancer therapy of gastric neoplasms. Asian Pac J Cancer Prev. 2012;13(5):2263-7. doi:10.7314/apjcp.2012.13.5.2263.

25. Zhang BG, Li JF, Yu BQ, Zhu ZG, Liu BY, Yan M. microRNA-21 promotes tumor proliferation and invasion in gastric cancer by targeting PTEN. Oncol Rep. 2012;27(4):1019-26. doi:10.3892/or.2012.1645.

26. Duan DM, Dong X, Tu Y, Liu P. A microarray study of chronic unpredictable mild stress rat blood serum with electro-acupuncture intervention. Neurosci Lett. 2016;627:160-7. doi:10.1016/j.neulet.2016.05.054.

27. Dong XZ, Zhao ZR, Hu Y, Lu YP, Liu P, Zhang L. LncRNA COL1A1-014 is involved in the progression of gastric cancer via regulating CXCL12-CXCR4 axis. Gastric Cancer. 2020;23(2):260-72. doi:10.1007/s10120-019-01011-0. 
28. Yao Y, Suo AL, Li ZF, Liu LY, Tian T, Ni L, Zhang WG, Nan KJ, Song TS, Huang C. MicroRNA profiling of human gastric cancer. Mol Med Rep. 2009;2(6):963-70. doi:10.3892/mmr_00000199.

29. Zhu ED, Li N, Li BS, Li W, Zhang WJ, Mao XH, Guo G, Zou QM, Xiao B. miR-30b, down-regulated in gastric cancer, promotes apoptosis and suppresses tumor growth by targeting plasminogen activator inhibitor-1. PLoS One. 2014;9(8):e106049. doi:10.1371/journal.pone.0106049.

30. Cho WJ, Shin JM, Kim JS, Lee MR, Hong KS, Lee JH, Koo KH, Park JW, Kim KS. miR-372 regulates cell cycle and apoptosis of ags human gastric cancer cell line through direct regulation of LATS2. Mol Cells. 2009;28(6):521-7. doi:10.1007/s10059-009-0158-0.

31. Zhang Z, Li Z, Gao C, Chen P, Chen J, Liu W, Xiao S, Lu H. miR-21 plays a pivotal role in gastric cancer pathogenesis and progression. Lab Invest. 2008;88(12):1358-66. doi:10.1038/labinvest.2008.94.

32. Bai Y, Kinne J, Ding L, Rath EC, Cox A, Naidu SD. Identification of genome-wide non-canonical spliced regions and analysis of biological functions for spliced sequences using Read-Split-Fly. BMC Bioinformatics. 2017;18(Suppl 11):382. doi:10.1186/s12859-017-1801-y.

33. Dang X, Qu X, Wang W, Liao C, Li Y, Zhang X, Xu D, Baglole CJ, Shang D, Chang Y. Bioinformatic analysis of microRNA and mRNA Regulation in peripheral blood mononuclear cells of patients with chronic obstructive pulmonary disease. Respir Res. 2017;18(1):4. doi:10.1186/s12931-016-0486-5.

34. Rachagani S, Macha MA, Menning MS, Dey P, Pai P, Smith LM, Mo YY, Batra SK. Changes in microRNA (miRNA) expression during pancreatic cancer development and progression in a genetically engineered KrasG12D;Pdx1-Cre mouse (KC) model. Oncotarget. 2015;6(37):40295-309. doi:10.18632/oncotarget.5641.

35. Wang R, Dong LD, Meng XB, Shi Q, Sun WY. Unique MicroRNA signatures associated with early coronary atherosclerotic plaques. Biochem Biophys Res Commun. 2015;464(2):574-9. doi:10.1016/j.bbrc.2015.07.010.

36. Elmore S. Apoptosis: a review of programmed cell death. Toxicol Pathol. 2007;35(4):495-516. doi:10.1080/01926230701320337.

37. Mohammad RM, Muqbil I, Lowe L, Yedjou C, Hsu HY, Lin LT, Siegelin MD, Fimognari C, Kumar NB, Dou QP, Yang H, Samadi AK, Russo GL, Spagnuolo C, Ray SK, Chakrabarti M, Morre JD, Coley HM, Honoki K, Fujii H, Georgakilas AG, Amedei A, Niccolai E, Amin A, Ashraf SS, Helferich WG, Yang X, Boosani CS, Guha G, Bhakta D, Ciriolo MR, Aquilano K, Chen S, Mohammed SI, Keith WN, Bilsland A, Halicka D, Nowsheen S and A. S. Azmi: Broad targeting of resistance to apoptosis in cancer. Semin Cancer Biol, 35 Suppl, S78-S103 (2015) doi:10.1016/j.semcancer.2015.03.001.

38. Cotter TG. Apoptosis and cancer: the genesis of a research field. Nat Rev Cancer. 2009;9(7):501-7. doi:10.1038/nrc2663.

39. Bang YJ, Kim YW, Yang HK, Chung HC, Park YK, Lee KH, Lee KW, Kim YH, Noh SI, Cho JY, Mok YJ, Kim YH, Ji J, Yeh TS, Button P, Sirzén F, Noh SH. Adjuvant capecitabine and oxaliplatin for gastric cancer after D2 gastrectomy (CLASSIC): a phase 3 open-label, randomised controlled trial. Lancet. 2012;379(9813):315-21. doi:10.1016/s0140-6736(11)61873-4. 
40. Zeeshan R, Mutahir Z. Cancer metastasis - tricks of the trade. Bosn J Basic Med Sci. 2017;17(3):172-82. doi:10.17305/bjbms.2017.1908.

41. Mendt M, Cardier JE. Role of SDF-1 (CXCL12) in regulating hematopoietic stem and progenitor cells traffic into the liver during extramedullary hematopoiesis induced by G-CSF, AMD3100 and PHZ. Cytokine. 2015;76(2):214-21. doi:10.1016/j.cyto.2015.05.004.

42. Arabanian LS, Fierro FA, Stölzel F, Heder C, Poitz DM, Strasser RH, Wobus M, Borhäuser M, Ferrer RA, Platzbecker U, Schieker M, Docheva D, Ehninger G, Illmer T. MicroRNA-23a mediates posttranscriptional regulation of CXCL12 in bone marrow stromal cells. Haematologica. 2014;99(6):9971005. doi:10.3324/haematol.2013.097675.

43. Itkin T, Gur-Cohen S, Spencer JA, Schajnovitz A, Ramasamy SK, Kusumbe AP, Ledergor G, Jung Y, Milo I, Poulos MG, Kalinkovich A, Ludin A, Kollet O, Shakhar G, Butler JM, Rafii S, Adams RH, Scadden DT, Lin CP, Lapidot T. Distinct bone marrow blood vessels differentially regulate haematopoiesis. Nature. 2016;532(7599):323-8. doi:10.1038/nature17624.

44. Zheng J, Wang $\mathrm{H}$, Zhou W. Modulatory effects of trophoblast-secreted CXCL12 on the migration and invasion of human first-trimester decidual epithelial cells are mediated by CXCR4 rather than CXCR7. Reprod Biol Endocrinol. 2018;16(1):17. doi:10.1186/s12958-018-0333-2.

45. Adelita T, Stilhano RS, Han SW, Justo GZ, Porcionatto M. Proteolytic processed form of CXCL12 abolishes migration and induces apoptosis in neural stem cells in vitro. Stem Cell Res. 2017;22:619. doi:10.1016/j.scr.2017.05.013.

46. Yu P, Zhang Z, Li S, Wen X, Quan W, Tian Q, Chen J, Zhang J, Jiang R. Progesterone modulates endothelial progenitor cell (EPC) viability through the CXCL12/CXCR4/PI3K/Akt signalling pathway. Cell Prolif. 2016;49(1):48-57. doi:10.1111/cpr.12231.

47. Kang H, Mansel RE, Jiang WG. Genetic manipulation of stromal cell-derived factor-1 attests the pivotal role of the autocrine SDF-1-CXCR4 pathway in the aggressiveness of breast cancer cells. Int J Oncol. 2005;26(5):1429-34.

48. Qu R, Sun Y, Li Y, Hu C, Shi G, Tang Y, Guo D. MicroRNA-130a-3p suppresses cell viability, proliferation and invasion in nasopharyngeal carcinoma by inhibiting CXCL12. Am J Transl Res. 2017;9(8):358698.

49. Zhou Y, Cao HB, Li WJ, Zhao L. The CXCL12 (SDF-1)/CXCR4 chemokine axis: Oncogenic properties, molecular targeting, and synthetic and natural product CXCR4 inhibitors for cancer therapy. Chin $\mathrm{J}$ Nat Med. 2018;16(11):801-10. doi:10.1016/s1875-5364(18)30122-5.

50. Hattermann K, Mentlein R. An infernal trio: the chemokine CXCL12 and its receptors CXCR4 and CXCR7 in tumor biology. Ann Anat. 2013;195(2):103-10. doi:10.1016/j.aanat.2012.10.013.

51. Esencay M, Sarfraz Y, Zagzag D. CXCR7 is induced by hypoxia and mediates glioma cell migration towards SDF-1a. BMC Cancer. 2013;13:347. doi:10.1186/1471-2407-13-347.

52. Mclver SC, Loveland KL, Roman SD, Nixon B, Kitazawa R, McLaughlin EA. The chemokine CXCL12 and its receptor CXCR4 are implicated in human seminoma metastasis. Andrology. 2013;1(3):51729. doi:10.1111/j.2047-2927.2013.00081.x. 
53. Luker KE, Lewin SA, Mihalko LA, Schmidt BT, Winkler JS, Coggins NL, Thomas DG, Luker GD. Scavenging of CXCL12 by CXCR7 promotes tumor growth and metastasis of CXCR4-positive breast cancer cells. Oncogene. 2012;31(45):4750-8. doi:10.1038/onc.2011.633.

54. Samarendra H, Jones K, Petrinic T, Silva MA, Reddy S, Soonawalla Z. and A. Gordon-Weeks: A metaanalysis of CXCL12 expression for cancer prognosis. Br J Cancer. 2017;117(1):124-35. doi:10.1038/bjc.2017.134.

55. Kurrey NK, Jalgaonkar SP, Joglekar AV, Ghanate AD, Chaskar PD, Doiphode RY, Bapat SA. Snail and slug mediate radioresistance and chemoresistance by antagonizing p53-mediated apoptosis and acquiring a stem-like phenotype in ovarian cancer cells. Stem Cells. 2009;27(9):2059-68. doi:10.1002/stem.154.

56. Liao YX, Zhou CH, Zeng H, Zuo DQ, Wang ZY, Yin F, Hua YQ, Cai ZD. The role of the CXCL12CXCR4/CXCR7 axis in the progression and metastasis of bone sarcomas (Review). Int J Mol Med. 2013;32(6):1239-46. doi:10.3892/ijmm.2013.1521.

57. Hwang TL, Lee LY, Wang CC, Liang Y, Huang SF, Wu CM. CCL7 and CCL21 overexpression in gastric cancer is associated with lymph node metastasis and poor prognosis. World J Gastroenterol. 2012;18(11):1249-56. doi:10.3748/wjg.v18.i11.1249.

58. Ying J, Xu Q, Zhang G, Liu B, Zhu L. The expression of CXCL12 and CXCR4 in gastric cancer and their correlation to lymph node metastasis. Med Oncol. 2012;29(3):1716-22. doi:10.1007/s12032-0119990-0.

59. Cheng Y, Qu J, Che X, Xu L, Song N, Ma Y, Gong J, Qu X, Liu Y. CXCL12/SDF-1a induces migration via SRC-mediated CXCR4-EGFR cross-talk in gastric cancer cells. Oncol Lett. 2017;14(2):2103-10. doi:10.3892/ol.2017.6389.

60. Xin Q, Zhang N, Yu HB, Zhang Q, Cui YF, Zhang CS, Ma Z, Yang Y, Liu W. CXCR7/CXCL12 axis is involved in lymph node and liver metastasis of gastric carcinoma. World $\mathrm{J}$ Gastroenterol. 2017;23(17):3053-65. doi:10.3748/wjg.v23.i17.3053.

\section{Tables}

\section{Table 1 Clinicopathological features of GC patients}




\begin{tabular}{|c|c|c|c|}
\hline Characteristic & & $\mathrm{n}=53$ & Proportion (\%) \\
\hline \multicolumn{4}{|l|}{ Gender } \\
\hline & Male & 32 & 60.38 \\
\hline & Female & 21 & 39.62 \\
\hline \multirow[t]{3}{*}{ Age (yr) } & Average age 53 & & \\
\hline & $<60$ & 35 & 66.04 \\
\hline & $\geq 60$ & 18 & 33.96 \\
\hline \multicolumn{4}{|l|}{ Differentiation } \\
\hline & Well & 36 & 67.92 \\
\hline & Poor & 17 & 32.08 \\
\hline \multicolumn{4}{|l|}{ Tumor size (cm) } \\
\hline & $<5$ & 37 & 69.81 \\
\hline & $\geq 5$ & 16 & 30.19 \\
\hline \multicolumn{4}{|c|}{ Lymph node metastasis } \\
\hline & Yes & 11 & 20.75 \\
\hline & No & 42 & 79.25 \\
\hline \multicolumn{4}{|l|}{ HP infection } \\
\hline & Yes & 28 & 52.83 \\
\hline & No & 25 & 47.17 \\
\hline \multicolumn{4}{|c|}{ CA125 level (ng/mL) } \\
\hline & $<40$ & 12 & 22.64 \\
\hline & $\geq 40$ & 41 & 77.36 \\
\hline
\end{tabular}

HP infection: $H$. pylori infection leading to chronic active gastritis, remains the main risk factor for gastric cancer. CA125 level: CA125 is most common in the serum of patients with epithelial ovarian tumors. Its positive rate in gastric cancer was quite high.

\section{Figures}


(a)

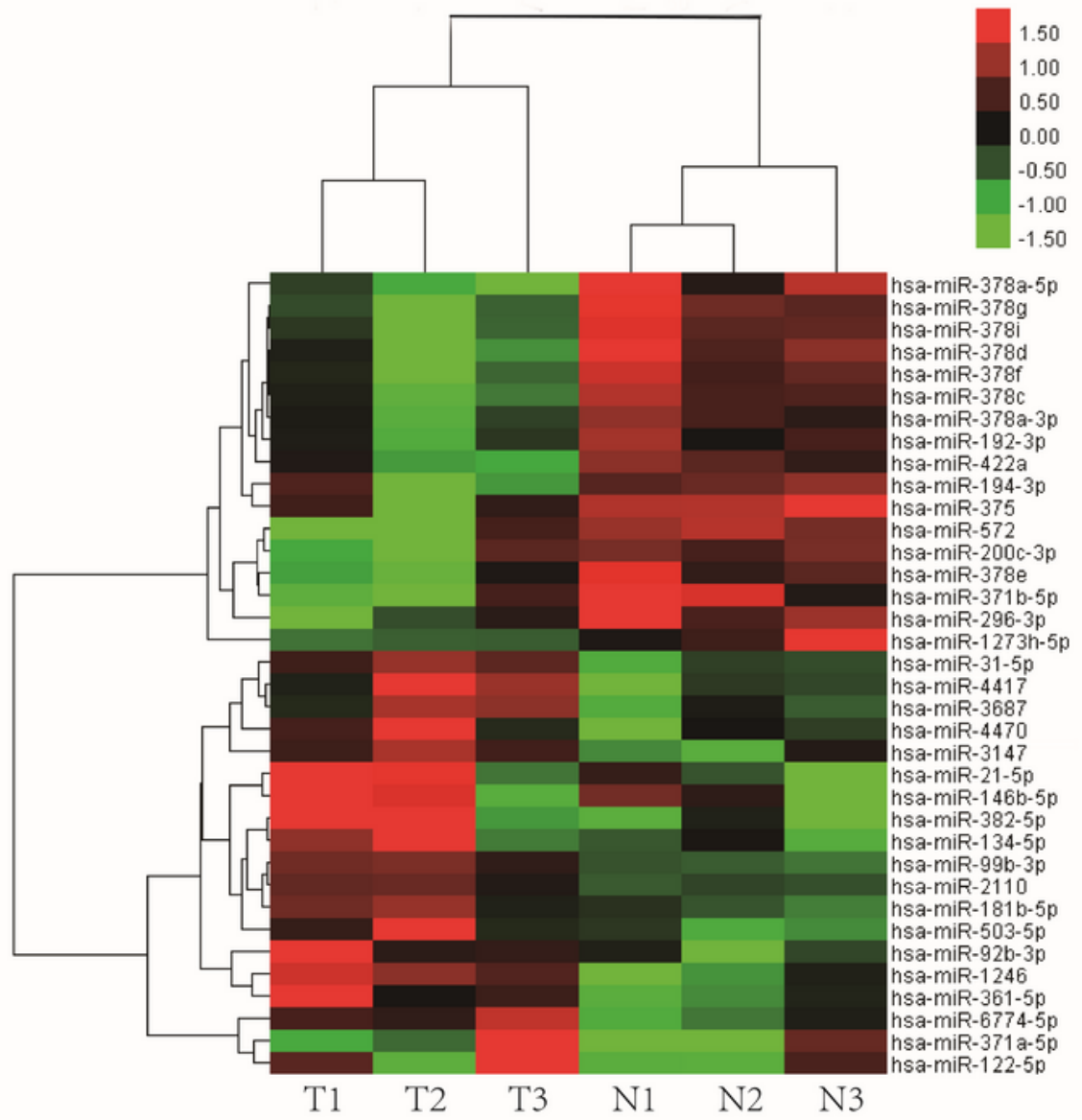

(b)

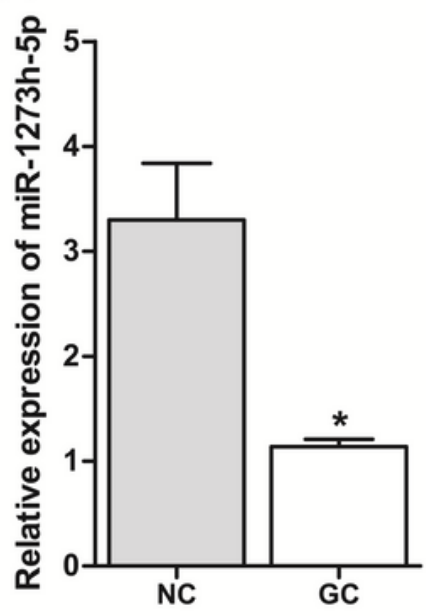

(c)

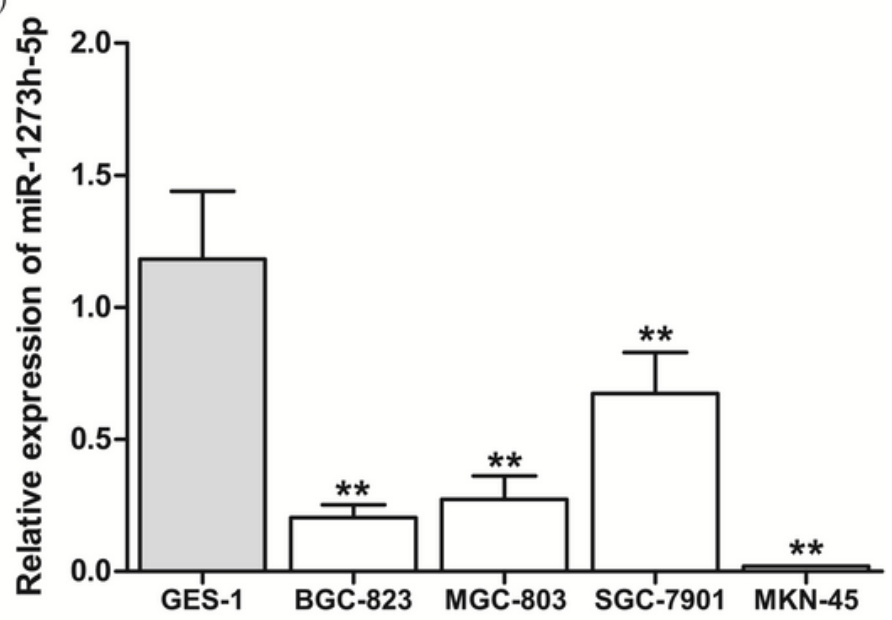

\section{Figure 1}

The analysis of differentially expressed miRNAs between GC and tumor-adjacent normal tissues. (a) Cluster analysis of differentially expressed miRNAs between GC and tumor-adjacent normal tissues by microarray assay. Each column indicates a sample, and each row shows the expression level of a gene. The green color indicates low expression, and the red color displays high expression. (b) The relative expression of miR-1273h-5p in 53 pairs of GC and tumor-adjacent normal tissues (NC) was analyzed by 
reverse transcription-polymerase chain reaction (RT-PCR). (c) The relative expression of miR-1273h-5p in GES-1 and GC cells determined by RT-PCR. *P $<0.05$; compared with GES-1 cells, ${ }^{*} P<0.05,{ }^{*} \mathrm{P}<0.01$.

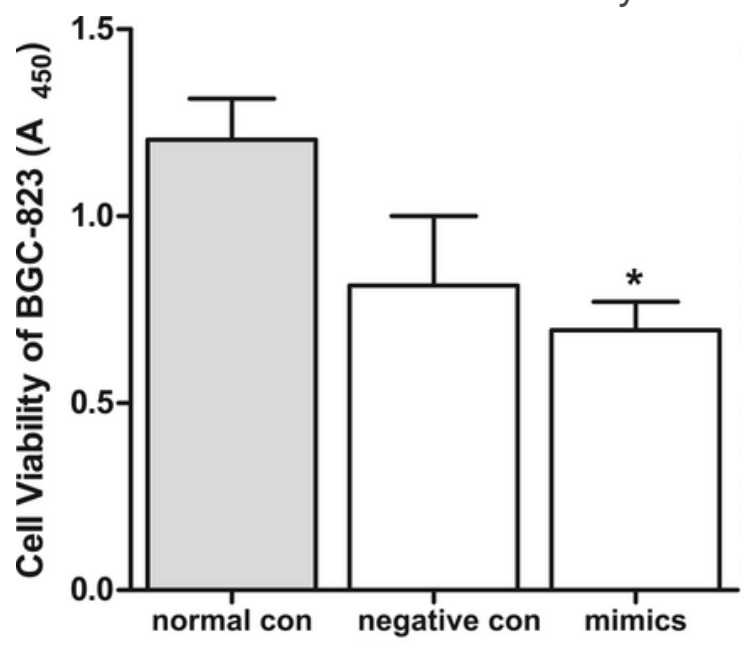

(a)

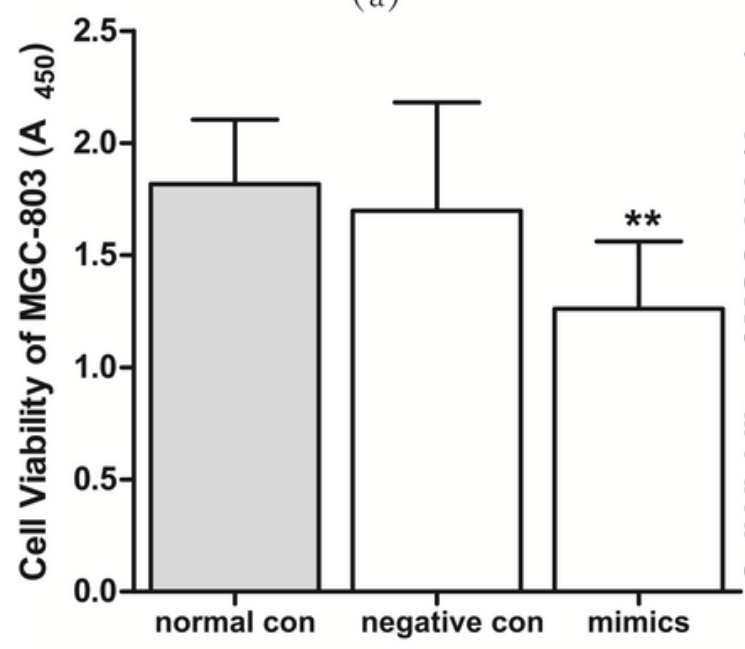

(c)

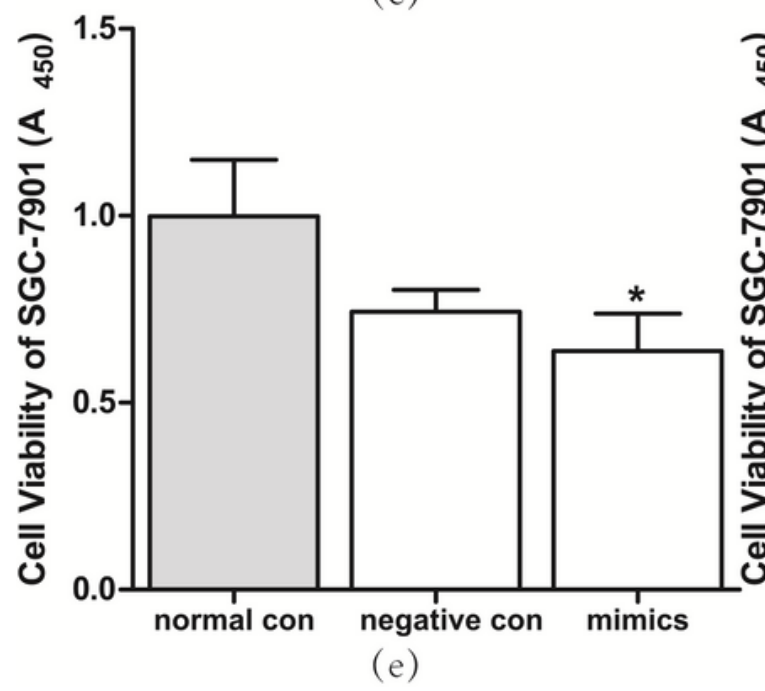

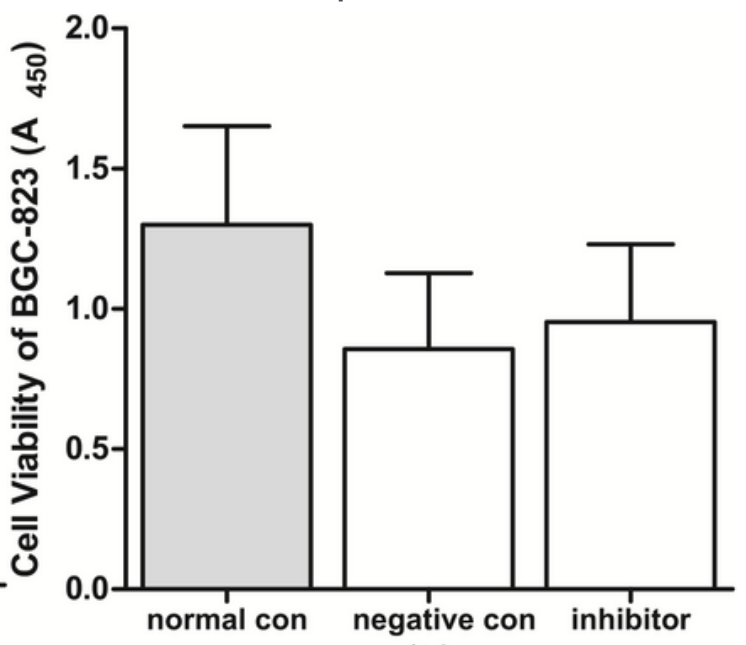

(b)

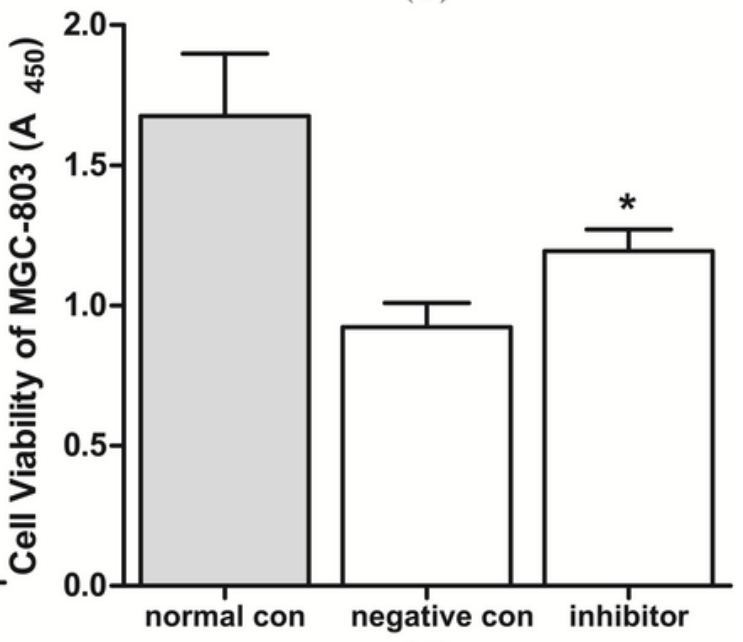

(d)

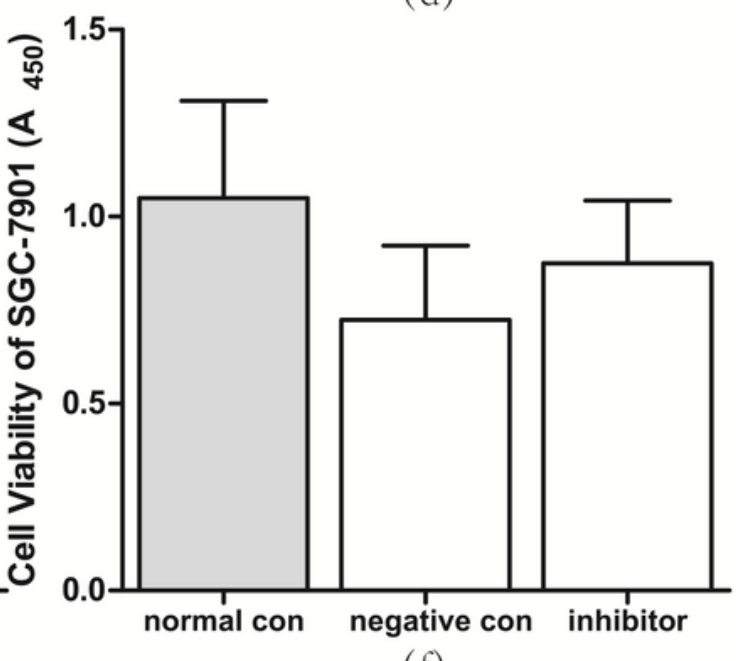

(f)

Figure 2

Impact of miR-1273h-5p on GC cell viability. $(a, b)$ Impact of miR-1273h-5p on the proliferation of BGC823 cells at $24 \mathrm{~h}$ after transfection evaluated by CCK-8 assay. Compared to negative control, the mimic group significantly decreased. (c, d) Effect of miR-1273h-5p on the proliferation of MGC-803 cells at $24 \mathrm{~h}$ 
after transfection evaluated by CCK-8 assay. Compared to a negative control group, the proliferation in the mimic group decreased while it increased in the inhibitor group. (e, f) Effect of miR-1273h-5p on the proliferation of SGC-7901 cells at $24 \mathrm{~h}$ after transfection evaluated by CCK-8 assay. The mimic group significantly decreased compared to a negative control. All data were expressed as mean \pm standard deviation $(\mathrm{M} \pm \mathrm{SD})$ from three independent experiments compared with the negative control group, ${ }^{*} \mathrm{P}$ $0.05, * * \mathrm{P}<0.01$.
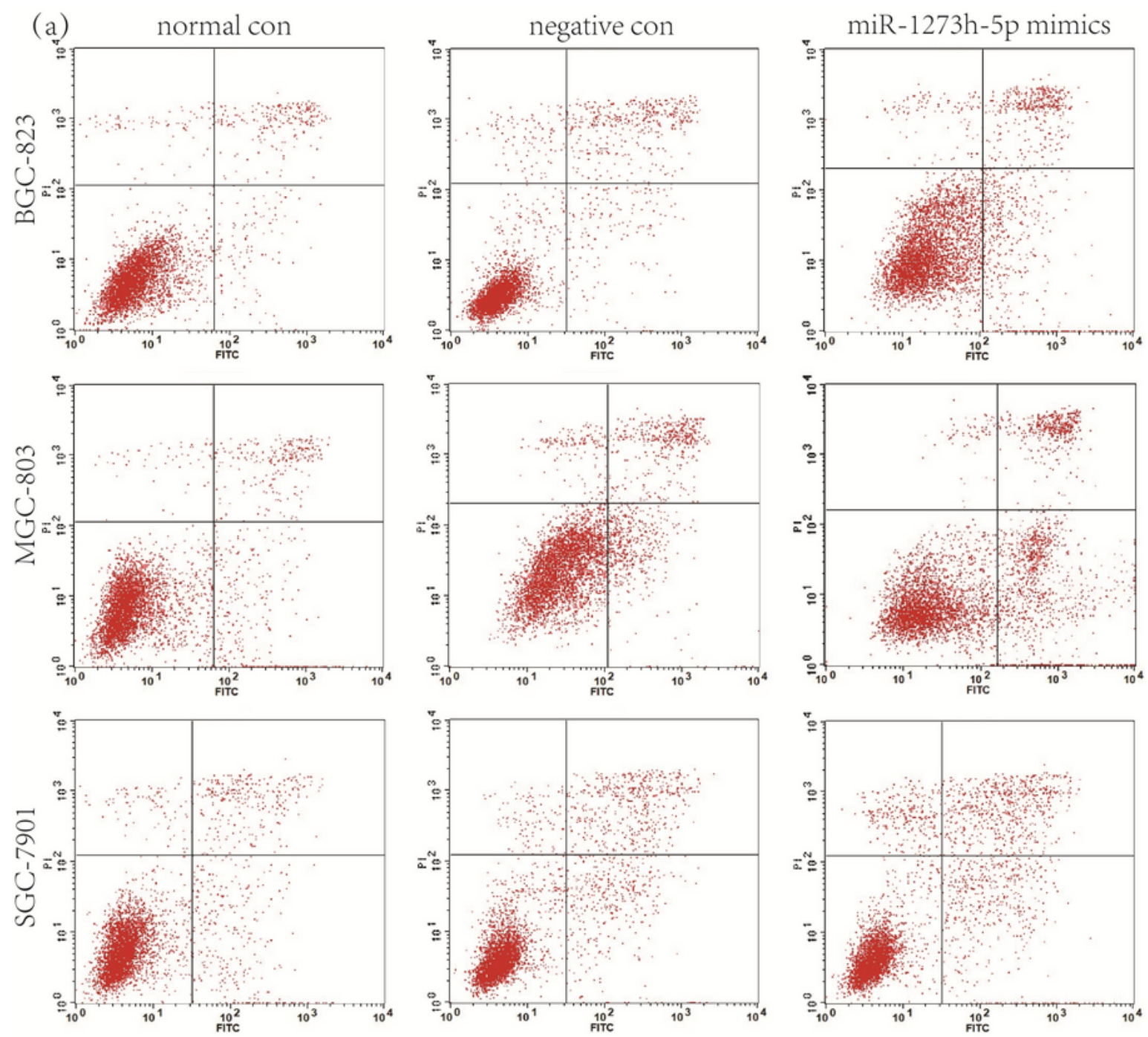

(b)

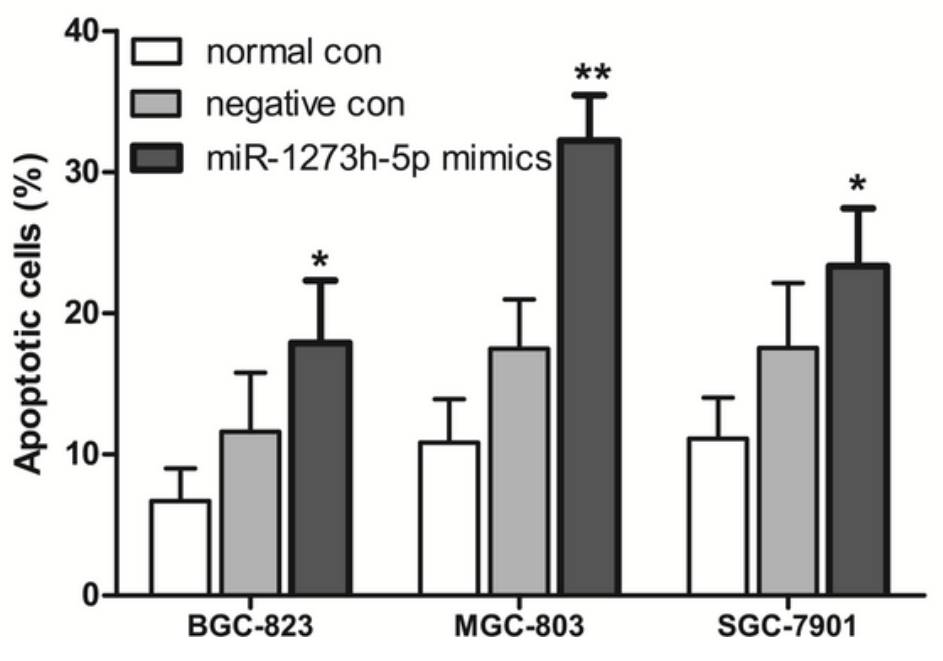

Figure 3 
Effect of miR-1273h-5p on GC cell apoptosis. (a) Effect of miR-1273h-5p on apoptosis of BGC-823, MGC803 , and SGC-7901 cells at $24 \mathrm{~h}$ after transfection evaluated by FCM. (b) Apoptotic rates of BGC-823, MGC-803, and SGC-7901 cells at $24 \mathrm{~h}$ after transfection of miR-1273h-5p mimic. Compared to the negative control, the apoptosis ratio of miR-1273h-5p mimics was significantly increased. All data were expressed as $\mathrm{M} \pm \mathrm{SD}$ from three independent experiments compared with the negative control group, ${ }^{*} \mathrm{P}<$ $0.05, * \star \mathrm{P}<0.01$.

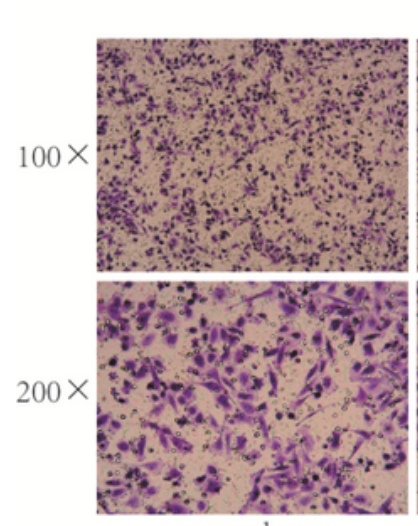

normal con

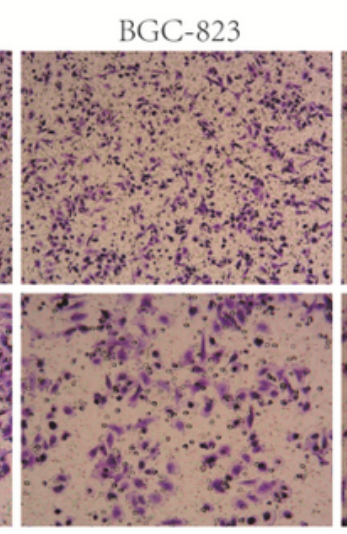

negative con

(a)

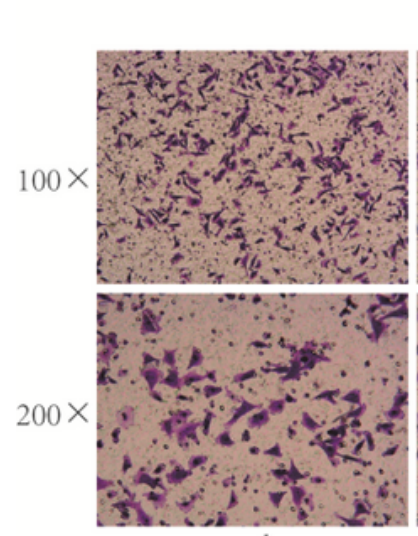

normal con

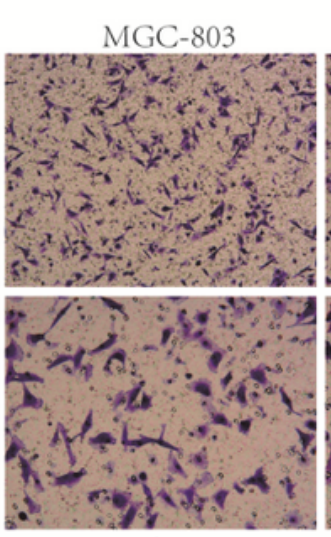

negative con (c)

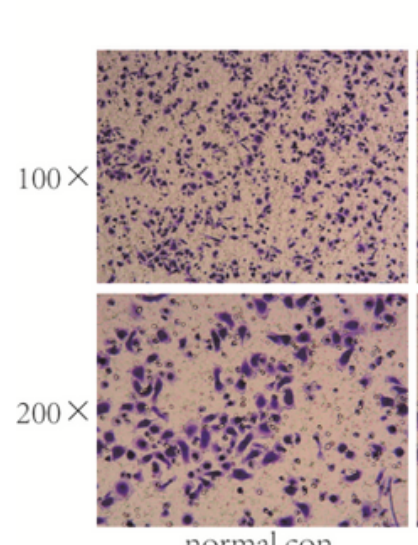

normal con

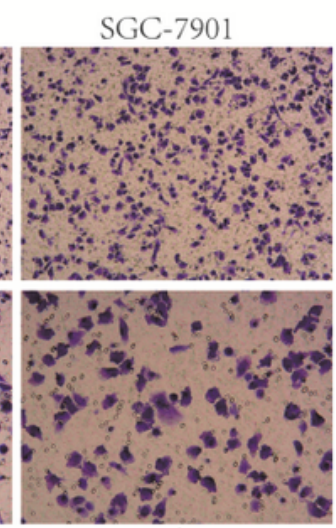

negative con

(e)

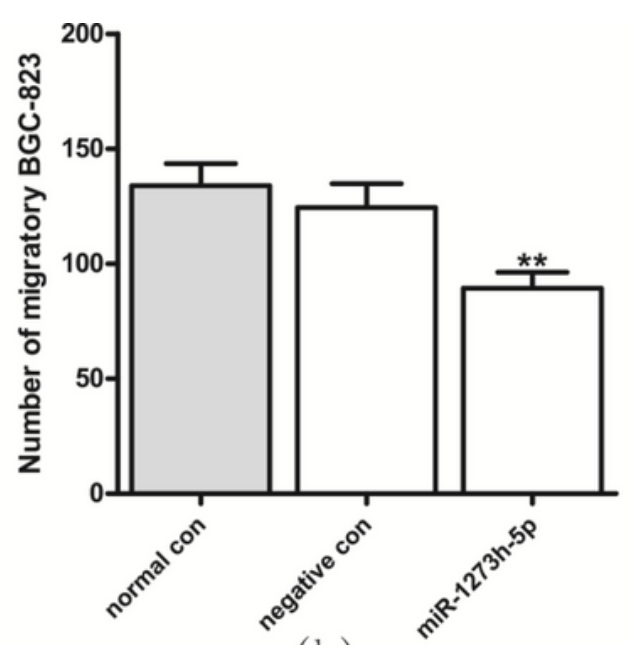

(b)

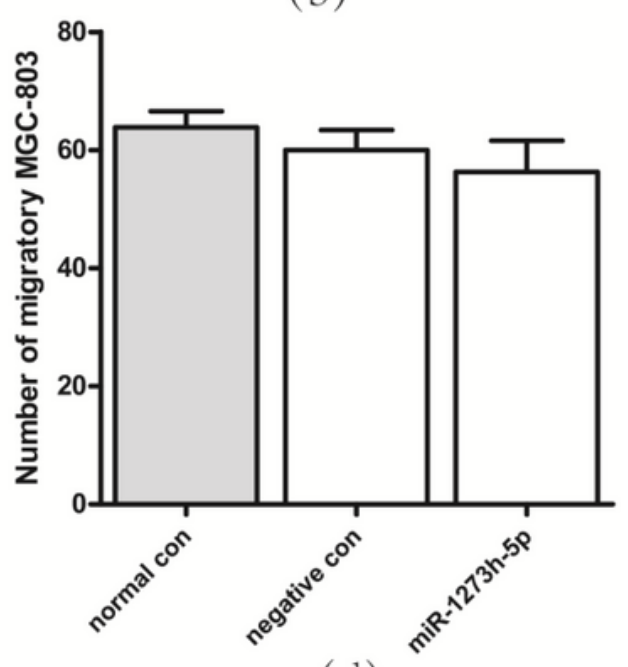

(d)

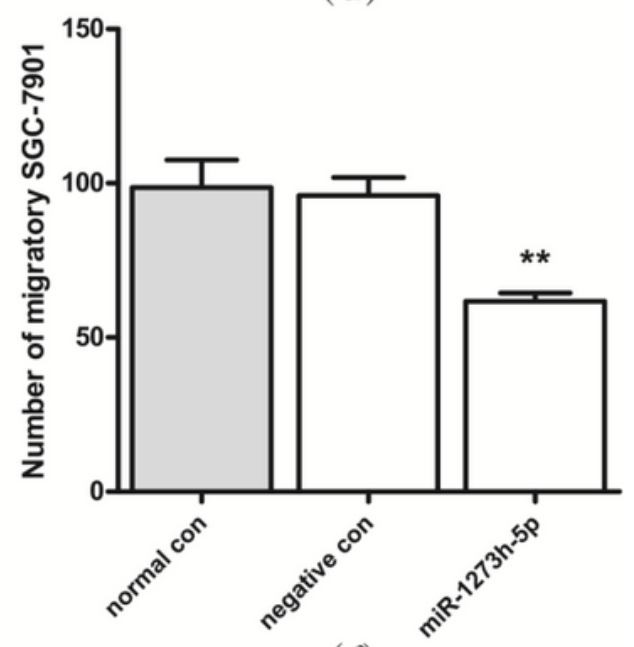

(f)

Figure 4 
Effect of miR-1273h-5p on GC cell migration. $(a, b)$ Effect of miR-1273h-5p on the migration of BGC-823 cells at $24 \mathrm{~h}$ after transfection determined by transwell assay. Compared to negative control, the ratio of migration was significantly reduced in the miR-1273h-5p group. (c, d) Impact of miR-1273h-5p on the migration of MGC-803 cells at $24 \mathrm{~h}$ after transfection determined by transwell assay. $(e, f)$ Impact of miR$1273 \mathrm{~h}-5 \mathrm{p}$ on the migration of SGC-7901 cells at $24 \mathrm{~h}$ after transfection determined by transwell assay. The migratory ratio of the miR-1273h-5p group revealed significantly decreased contrast with negative control. All data were expressed as $\mathrm{M} \pm \mathrm{SD}$ from three independent experiments when compared with the

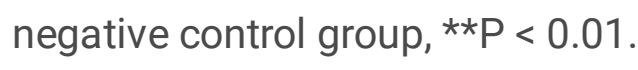




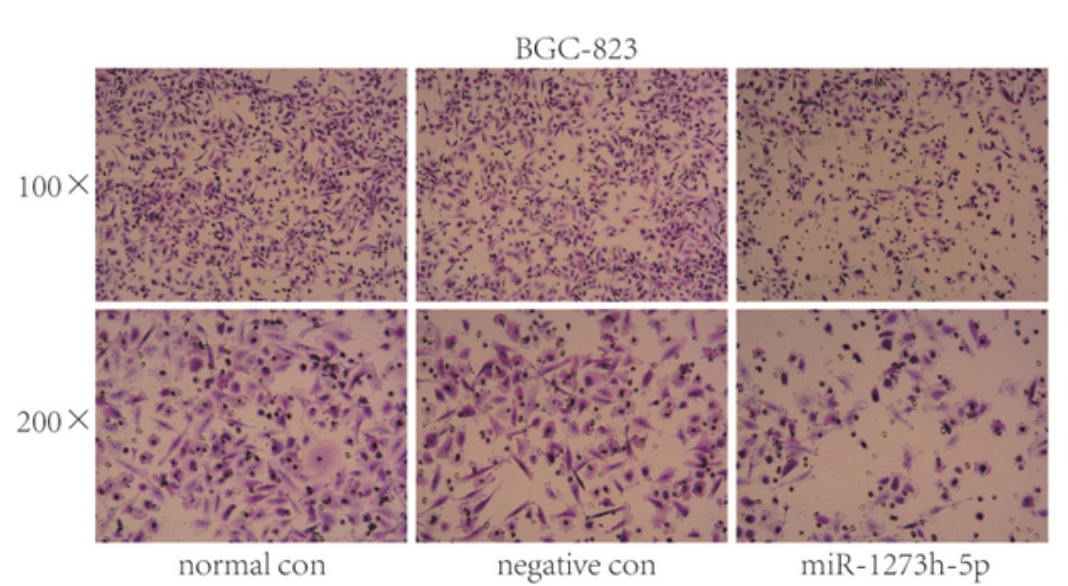

(a)

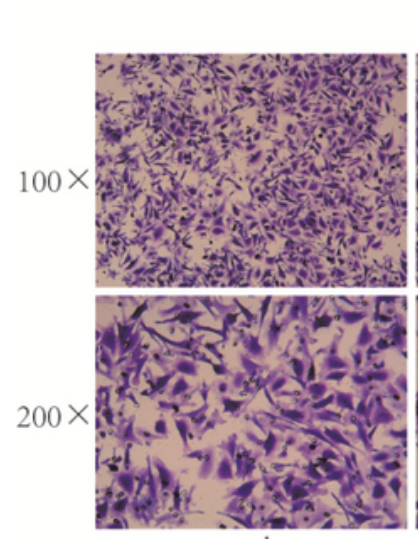

normal con

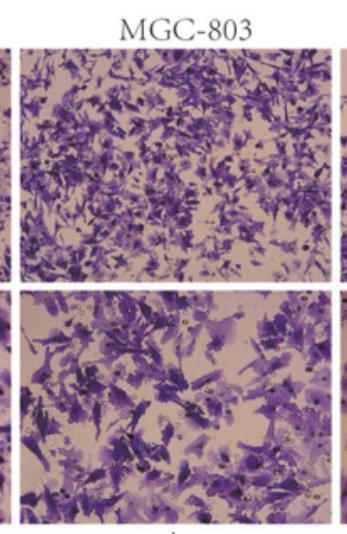

negative con

(c)

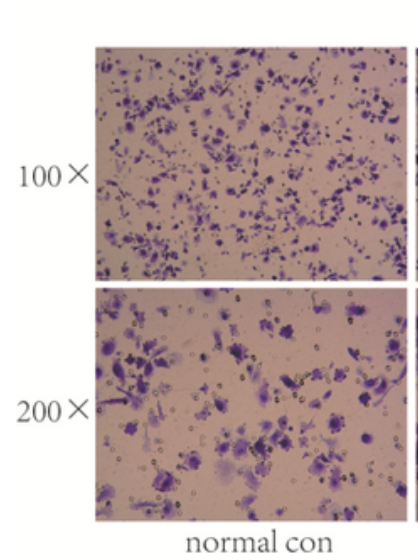

normal con

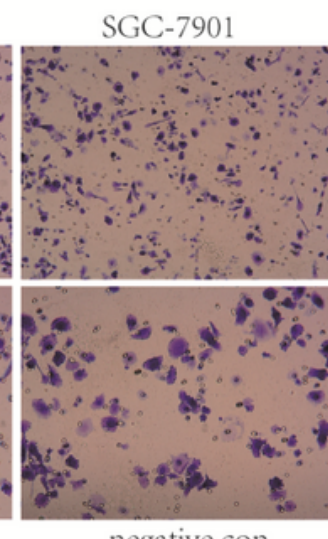

negative con

(e)

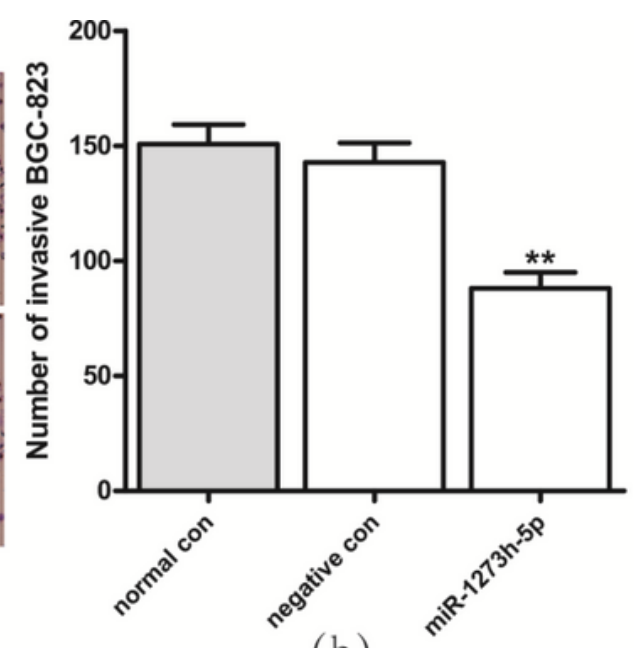

(b)

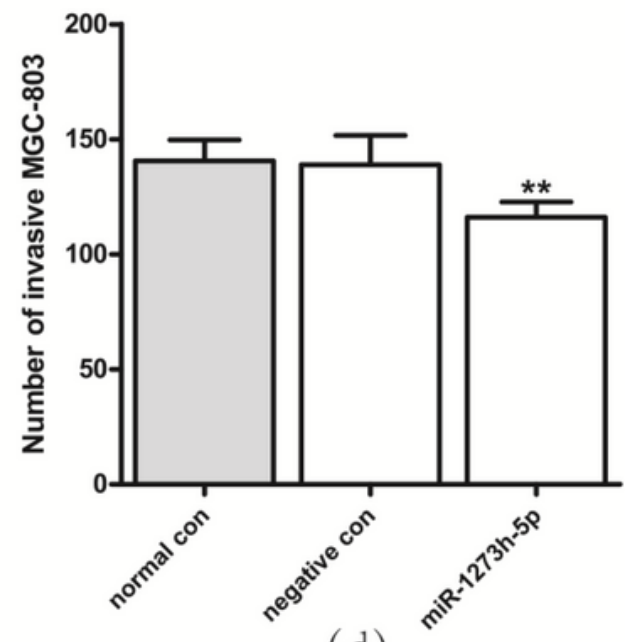

(d)

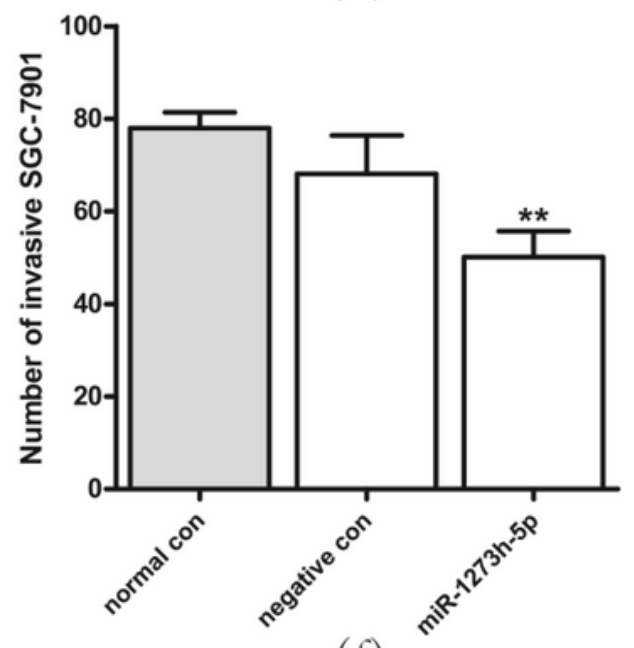

(f)

\section{Figure 5}

Effect of miR-1273h-5p on GC cell invasion. (a, b) Effect of miR-1273h-5p on the invasion of BGC-823 cells at $24 \mathrm{~h}$ after transfection determined by transwell assay. (c, d) Impact of miR-1273h-5p on the invasion of MGC-803 cells at $24 \mathrm{~h}$ after transfection determined by transwell assay. (e, f) Impact of miR1273h-5p on the invasion of SGC-7901 cells at $24 \mathrm{~h}$ after transfection determined by transwell assay. The miR-1273h-5p group had a significant decrease in contrast with the negative group in three cell models. 
All data were expressed as $\mathrm{M} \pm \mathrm{SD}$ from three independent experiments compared with the negative control group, ${ }^{\star *} \mathrm{P}<0.01$.

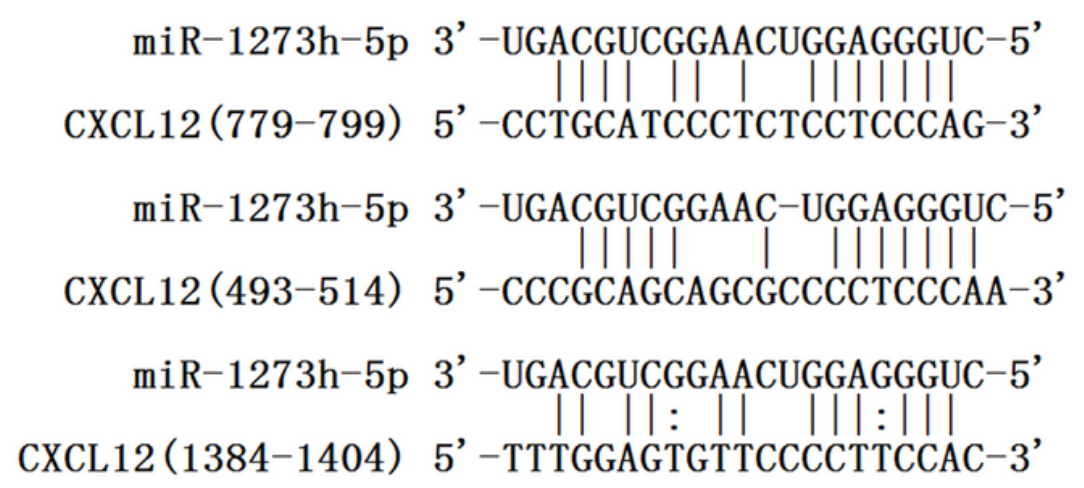

(a)

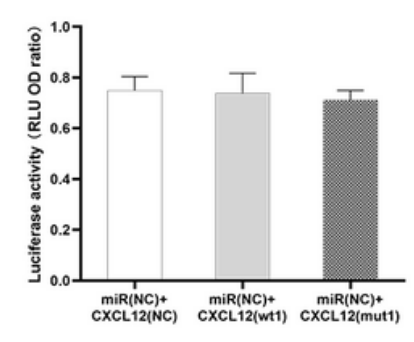

(b)

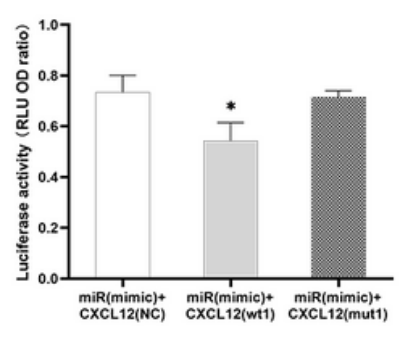

(c)

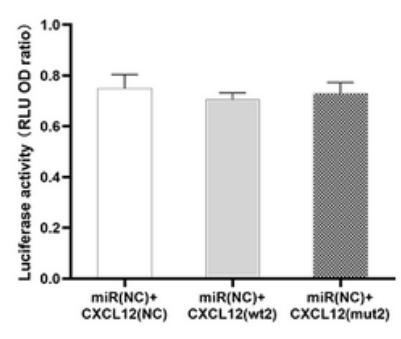

(d)

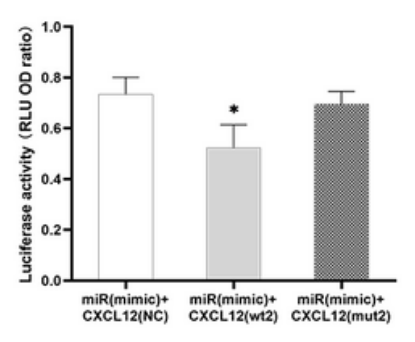

(e)

\section{Figure 6}

Bioinformatic analysis of miR-1273h-5p and target gene correlation. (a) Potential targeting (binding) site of miR-1273h-5p on CXCL12 mRNA predicted by using TargetScan and miRanda software. (b, d) After the combination of microRNA negative control plasmid with CXCL12 plasmids, including negative control, wide type 1 (2), and mutation 1 (2), no statistical difference was found in the RLU ratio. (c, e) In comparison with the other two groups, the RLU ratio of microRNA mimic combined with CXCL12 wide type 1(2) plasmid significantly decreased. All transfection trials were conducted using the HKE293 cells. ( $\star P<0.05, * * P<0.01)$ 


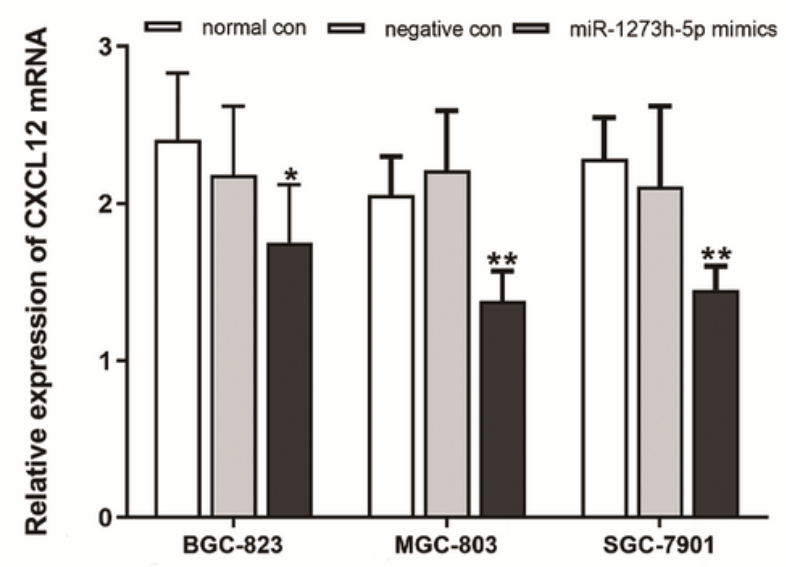

(a)

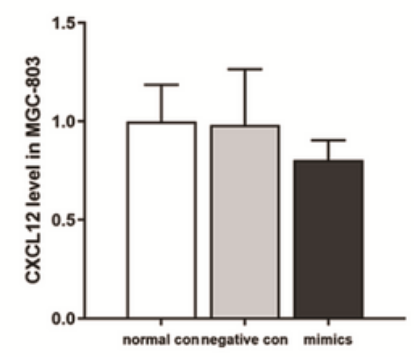

(d)

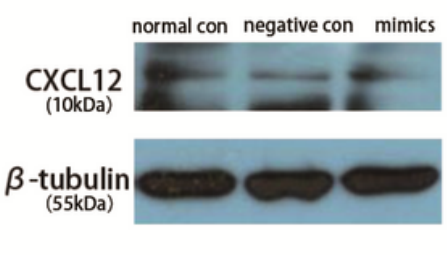

(e)

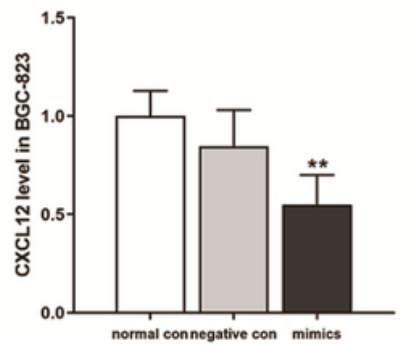

(b)

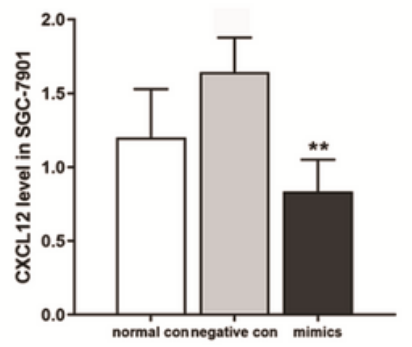

(f)

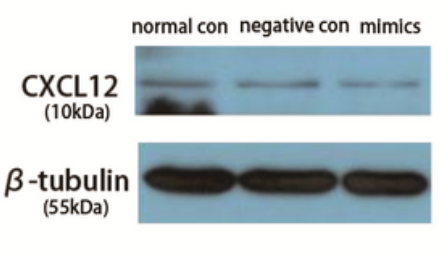

(c)

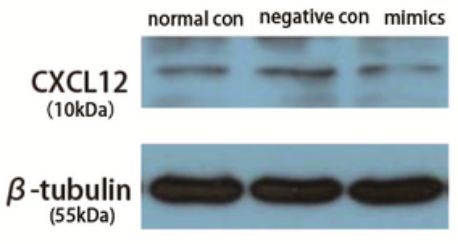

(h)

\section{Figure 7}

Verification of target gene CXCL12 in GC cells. (a) The expression of CXCL12 at the mRNA level in BGC823, MGC-803, and SGC-7901 cells following miR-1273h-5p mimic transfection was evaluated by RT-PCR. MiR-1273h-5p mimic group revealed a significant decrease compared to the negative group in three gastric cancer cells. $(b, d, f)$ The expression of CXCL12 at the protein level in BGC-823, MGC-803, and SGC-7901 cells following miR-1273h-5p mimic transfection determined by Western blot. The expression of CXCL12 in mimics revealed a significant reduction of BGC-823 and SGC-7901cells by contrast with negative control. (c, e, h) Protein electrophoretic bands of BGC-823, MGC-803, and SGC-7901 cells, respectively. All data were represented as $\mathrm{M} \pm \mathrm{SD}$ from three independent experiments compared with the negative control group, ${ }^{*} \mathrm{P}<0.05, * * \mathrm{P}<0.01$. 


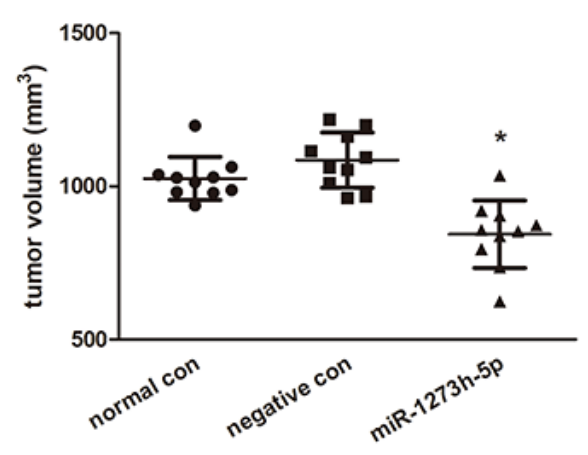

(a)

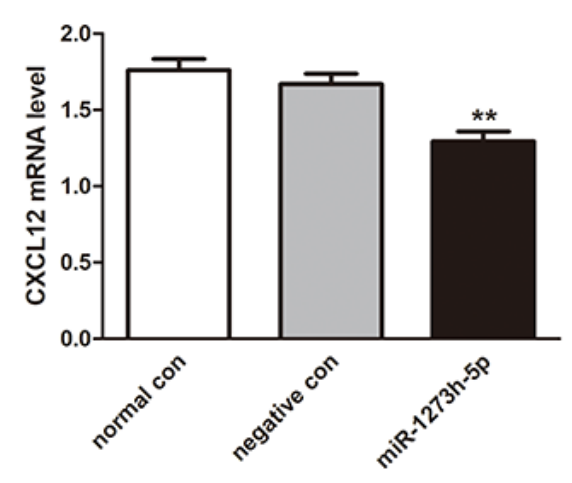

(d)

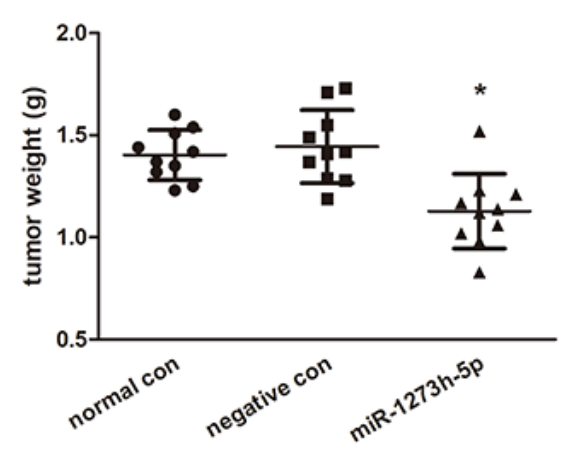

(b)

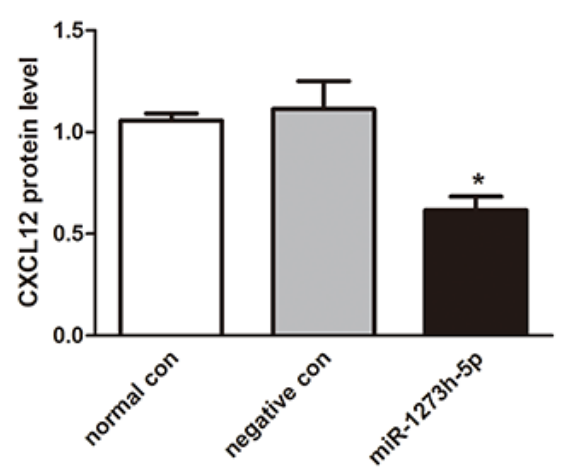

(e)

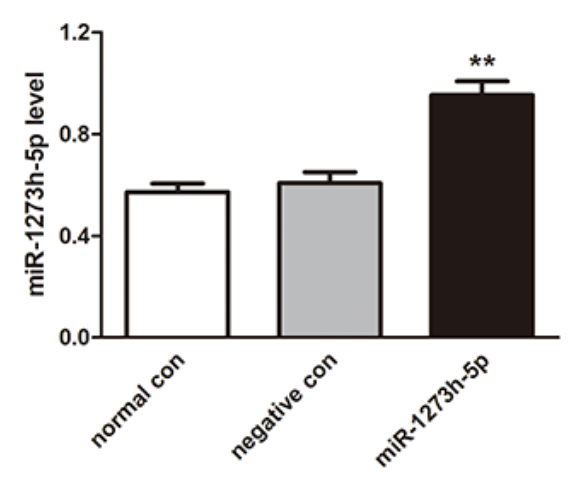

(c)

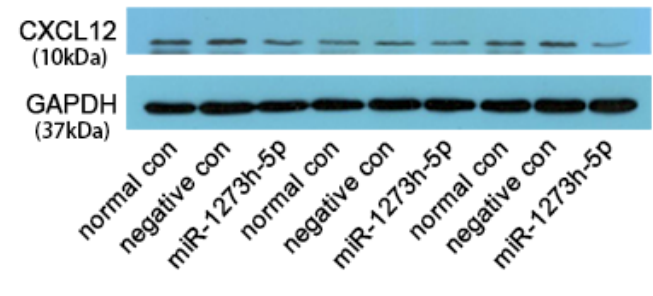

(f)

\section{Figure 8}

Effect of miR-1273h-5p on SGC-7901 cell transplanted mice model. $(a, b)$ Tumor volume and weight of cancer tissue among the normal control group, negative control group, and miR-1273h-5p group MiR1273h-5p group revealed a significant reduction in comparison to negative control. (c, d) The expression of miR-1273h-5p and CXCL12 at the mRNA level in normal control, negative control, and the miR-1273h$5 p$ transfected group was evaluated by RT-PCR. In contrast with negative group, the miR-1273h-5p group significantly increased. $(\mathrm{e}, \mathrm{f})$ The expression of CXCL12 at the protein level in three groups determined by Western blotting analysis. The miR-1273h-5p group significantly decreased compared to the negative group. All data were represented as $\mathrm{M} \pm \mathrm{SD}$ from three independent experiments compared with the negative control group, ${ }^{\mathrm{P}}<0.05,{ }^{\star *} \mathrm{P}<0.01$.

\section{Supplementary Files}

This is a list of supplementary files associated with this preprint. Click to download.

- FigureS1.jpg

- tablesupplement.docx 